\title{
PLOS Neglected Tropical Diseases
}

\section{Factors associated with soil-transmitted helminth infection in Benin: findings from the DeWorm3 study \\ --Manuscript Draft--}

\begin{tabular}{|c|c|}
\hline Manuscript Number: & PNTD-D-20-02235 \\
\hline Full Title: & $\begin{array}{l}\text { Factors associated with soil-transmitted helminth infection in Benin: findings from the } \\
\text { DeWorm3 study }\end{array}$ \\
\hline Short Title: & Deworm3 study findings of factors associated with STH infection in Benin. \\
\hline Article Type: & Research Article \\
\hline Keywords: & Soil Transmitted Helminths, prevalence, risk factor, DeWorm3, Comé, Benin \\
\hline Abstract: & 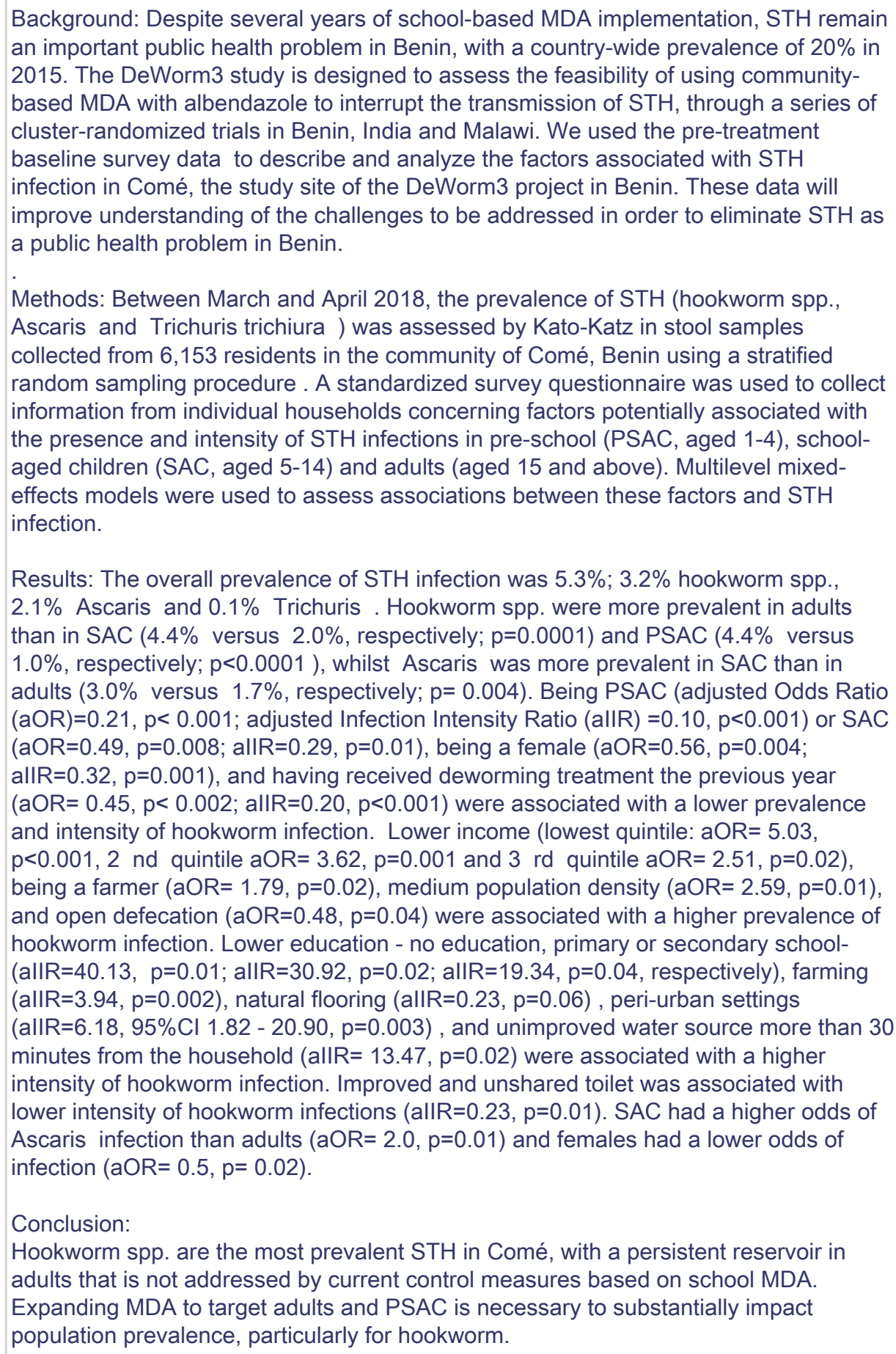 \\
\hline
\end{tabular}




\section{Additional Information:}

Question

\section{Response}

\section{Financial Disclosure}

JLW and TL received the DeWorm3 study funding from The Bill and Melinda Gates foundation (OPP1129535). https://www.gatesfoundation.org/. The funders had no role

Enter a financial disclosure statement that in study design, data collection and analysis, decision to publish, or preparation of the describes the sources of funding for the work included in this submission. Review the submission guidelines for detailed requirements. View published research articles from PLOS NTDs for specific examples. manuscript.

EA is a PhD candidate at the University of Paris. His research is funded by DeWorm3 as a staff member of the Benin coordinating team, and by the French Research Institute for Sustainable Development (IRD) through the International Mixed Laboratory LMI CONS_HELM (helminth infections: treatments and consequences on health and development in the South).

https://www.ird.fr/benin/partenariat

This statement is required for submission and will appear in the published article if the submission is accepted. Please make sure it is accurate.

\section{Unfunded studies}

Enter: The author(s) received no specific funding for this work.

\section{Funded studies}

Enter a statement with the following details:

- Initials of the authors who received each award

- Grant numbers awarded to each author

- The full name of each funder

- URL of each funder website

- Did the sponsors or funders play any role in the study design, data collection and analysis, decision to publish, or preparation of the manuscript?

- NO - Include this sentence at the end of your statement: The funders had no role in study design, data collection and analysis, decision to publish, or preparation of the manuscript.

- YES - Specify the role(s) played.

* typeset

\section{Competing Interests}

The authors have declared that no competing interests exist. 
Use the instructions below to enter a competing interest statement for this submission. On behalf of all authors, disclose any competing interests that could be perceived to bias this work-acknowledging all financial support and any other relevant financial or nonfinancial competing interests.

This statement will appear in the published article if the submission is accepted. Please make sure it is accurate. View published research articles from PLOS NTDs for specific examples.

\section{NO authors have competing interests}

Enter: The authors have declared that no competing interests exist.

\section{Authors with competing interests}

Enter competing interest details beginning with this statement:

I have read the journal's policy and the authors of this manuscript have the following competing interests: [insert competing interests here]

* typeset

\section{Data Availability}

No - some restrictions will apply

Authors are required to make all data underlying the findings described fully available, without restriction, and from the 
time of publication. PLOS allows rare exceptions to address legal and ethical concerns. See the PLOS Data Policy and $F A Q$ for detailed information.

A Data Availability Statement describing where the data can be found is required at submission. Your answers to this question constitute the Data Availability Statement and will be published in the article, if accepted.

Important: Stating 'data available on request from the author' is not sufficient. If your data are only available upon request, select 'No' for the first question and explain your exceptional situation in the text box.

Do the authors confirm that all data underlying the findings described in their manuscript are fully available without restriction?

Describe where the data may be found in full sentences. If you are copying our sample text, replace any instances of $X X X$ with the appropriate details.

- If the data are held or will be held in a public repository, include URLs, accession numbers or DOls. If this information will only be available after acceptance, indicate this by ticking the box below. For example: $A$ II $X X X$ files are available from the $X X X$ database (accession number(s) $X X X, X X X$.).

- If the data are all contained within the manuscript and/or Supporting Information files, enter the following: All relevant data are within the manuscript and its Supporting Information files.
Data cannot be shared publicly because the study remains blinded. to outcome data. Data are available from the DeWorm3 Institutional Data Access Committee (contact via Barbra Richardson, barbrar@uw.edu) for researchers who meet the criteria for access to these data. 
- If neither of these applies but you are able to provide details of access elsewhere, with or without limitations, please do so. For example:

Data cannot be shared publicly because of [XXX]. Data are available from the $X X X$ Institutional Data Access / Ethics Committee (contact via $X X X)$ for researchers who meet the criteria for access to confidential data.

The data underlying the results presented in the study are available from (include the name of the third party and contact information or URL).

- This text is appropriate if the data are owned by a third party and authors do not have permission to share the data.

* typeset

Additional data availability information:

Tick here if the URLs/accession numbers/DOls will be available only after acceptance of the manuscript for publication so that we can ensure their inclusion before publication.; Tick here if your circumstances are not covered by the questions above and you need the journal's help to make your data available. 
1 Factors associated with soil-transmitted helminth infection in Benin: findings

2 from the DeWorm3 study

3

4

5

6

7

Euripide F G A Avokpaho ${ }^{1,2 \star}$, Parfait Houngbégnon ${ }^{1}$, Manfred Accrombessi ${ }^{1}$, Eloic Atindegla ${ }^{1}$, Elodie Yard ${ }^{3}$, Arianna Rubin Means ${ }^{3,4}$, Timothy J Littlewood ${ }^{5}$, André Garcia $^{6}$, Achille Massougbodji1, Sean Galagan ${ }^{4}$, Judd L Walson ${ }^{3,4}$, Gilles Cottrell ${ }^{6}$, Moudachirou Ibikounlé ${ }^{1,7 \star}$, Kristjana Hrönn Ásbjörnsdóttir ${ }^{3,4 *}$, Adrian J F Luty6*

- Corresponding author: Euripide F G A Avokpaho, email:

euripideavokpaho@gmail.com

* Joint co-last authors

Authors affiliations:

${ }^{1}$ Institut de Recherche Clinique du Bénin, Abomey-Calavi, Quartier Zopah Lot 641, 04 BP 1114, Benin.

'Université de Paris, 12 Rue de l'École de Médecine, 75006 Paris, France

${ }^{3}$ DeWorm3, Division of Life Sciences, Natural History Museum, London, United Kingdom.

${ }^{4}$ Department of Global Health, University of Washington, Seattle, United States.

${ }^{5}$ Blantyre Institute for Community Outreach, Lions Sight First Eye Hospital, Blantyre, Malawi.

6Université de Paris, MERIT, IRD, F-75006 Paris, France

7 Centre de Recherche pour la lutte contre les Maladies Infectieuses Tropicales (CReMIT), Université d'Abomey-Calavi, 01BP526, Cotonou, Bénin

\section{Introduction}

Soil-transmitted helminth (STH) infections are among the most common infections worldwide, affecting more than 1.5 billion of the poorest and most marginalized communities globally. (1) The most common STH species of humans include Ascaris lumbricoides, Trichuris trichiura and the hookworm species, Necator americanus and Ancylostoma duodenale. STH cur transmitted by eggs present in human feces, which in turn contaminate soil and water in areas with poor sanitation, conditions often found 
in low-resource countries. (2) STH are widely distributed in tropical and subtropical areas, with the greatest numbers occurring in sub-Saharan Africa, the Americas, China and East Asia. (3)

The World Health Organization (WHO) considers STH a public health problem in areas where $>1 \%$ of the at-risk population has moderate-to-heavy intensity infection - as measured by number of eggs per gram of stool diagnosed, by stool examination (4). These moderate to high intensity helminth infections are associated with poor cognitive and motor outcomes in infants, as well as with anemia. (5-9) Pre-school children (PSAC), school age children (SAC) and women of reproductive age (WRA), including adolescent girls, pregnant women, lactating women, and non-pregnant and nonlactating women living in endemic areas, are at highest risk of morbidity due to $\mathrm{STH}_{\text {. }}$ Clear policy and guidance are essential to support country-level efforts to expand routine deworming of WRA, and recent WHO publications have provided the necessary policy framework. $(2,3)$

The WHO Neglected Tropical Disease (NTD) Roadmap and London Declaration have accelerated progress toward eliminating selected NTDs, including lymphatic filariasis and onchocerciasis, and formalized long-term disease-specific goals for other NTDs. (10) Global interest is shifting towards an elimination strategy for other NTDs, including the possibility of breaking the transmission of STH through community-wide mass drug administration (MDA). (11)

In Benin, all major STH (hookworm sp., A. lumbricoides and $T$. trichiura) ure a recognized public health problem, with more than $50 \%$ of districts requiring MDA based on the results of a recent national mapping exercise that sampled stool from SAC. $(12,13)$ In Comé District, this recent national mapping showed a prevalence of STH in school-aged children of $20 \%$, despite multiple rounds of school-based MDA with albendazole in 2015 (coverage 59\%), 2016 (coverage 78\%) and 2017 (coverage 83\%). (13)

In 2017, the DeWorm3 project (ClinicalTrials.gov Identifier NCT03014167) was initiated in Benin, and, in parallel, in India and Malawi. Using a cluster randomized controlled study design, the primary objective of the project is to determine whether 
the provision of an enhanced (twice yearly) level of high-coverage MDA, targeting all age groups in a whole community over a 3-year period, can interrupt transmission of STH (11). Here we report analyses of baseline data from a longitudinal monitoring cohort randomly selected from the whole population involved in the trial in order to determine the demographic and other parameters potentially associated with the STH infections detected by microscopy using a standard Kato-Katz procedure.

\section{Materials and Methods}

\section{Study area and population}

The DeWorm3 trial in Benin is being conducted in the district of Comé. The study site selection was based on criteria reported previously. (14) Comé is located $70 \mathrm{~km}$ west of Cotonou in the Mono department, at latitude $6^{\circ} 24^{\prime} \mathrm{N}$ and longitude $1^{\circ} 53^{\prime} \mathrm{E}$. The district covers an area of $153 \mathrm{~km}^{2}$ with a population estimated at 79,989 inhabitants in the census of 2012 , with an estimated yearly growth rate of $2.07 \%$. , Tiv) The district has five sub-districts (Central Comé, Akodéha, Oumako, Agatogbo and OuèdèmèPedah) subdivided into 52 villages/areas or neighborhoods. The climate is subequatorial, tropical, alternating between two rainy seasons (April to July and September to November) and two dry seasons (December to March and August). Rainfall varies between 900 and 1,200 mm per year.

\section{Study design}

The protocol and aims of the DeWorm3 study have been published elsewhere. (11) A baseline census was conducted from January $8^{\text {th }}$ to February $9^{\text {th }}, 2018$ followed by cluster demarcation. The geospatial locations of all households were mapped using ArcGIS (Redlands, CA), and the study area was divided into 40 clusters with between 1,650 and 4,000 residents per cluster. From March $6^{\text {th }}$ to April $5^{\text {th }}, 2018,6000$ individuals (150 individuals by cluster) were randomly selected to constitute a longitudinal monitoring cohort (LMC) participating in annual follow-up STH infection surveys over 5 years. The LMC was selected from the censused population using stratified random sampling of PSAC aged 1-4 years old, SAC aged 5-14 years old and adults aged 15 years old and above, at a ratio of 1:1:3. A sampling list of 150 individuals (i.e. 30 PSAC, 30 SAC and 90 adults) was initially generated and backup lists of 75 
individuals were issued to replace participants who could not be located or refused to participate. LMC participants were interviewed and completed a more in-depth assessment of individual-level STH risk factors, including a survey of self-reported WASH access and use, history of deworming, and direct observation of WASH facilities and participants' use of footwear. Individuals participating in the LMC agreed to provide stool samples for immediate analysis using the Kato-Katz method (16) annually for the duration of the study.

\section{Data collection}

\section{Kato-Katz data}

Stool samples from LMC participants were collected by study staff and delivered to the laboratory within one hour. Samples were screened using the Kato-Katz technique, with results for each type of helminth (A. lumbricoides, T. trichiura and hookworm: $A$. duodenale/N. americanus) reported in eggs per gram ( $\overline{\bar{n}}$. 3$)$. Two slides were prepared from each sample, and each slide was examined by two experienced lab technicians. A subset of $10 \%$ of slides was randomly selected for quality assurance by a laboratory manager. Prevalence was calculated both for individual STH types and cumulatively according to the following formulas:

- The prevalence per STH type:

$$
p=\frac{\text { Number of samples where at least one egg of STH species is found }}{\text { total number of samples examined }} \times 100
$$

- The cumulative STH prevalence:

$$
p=\frac{\text { Number of positive samples for one, two or three STH species }}{\text { total number of samples examined }} \times 100
$$

In cases of co-infection, the sample was counted to calculate the cumulative prevalence, and prevalence and intensity assessed separately for each species. The parasite intensity was calculated from a Kato-Katz smear made with $41.7 \mathrm{mg}$ of stool, by multiplying the egg count from the slide by a factor of $24(24 \times 41.7 \mathrm{mg} \approx 1 \mathrm{~g})_{\text {; }}$ to $g$ get the number of eggs per gram of stool (EPG) 
The primary outcomes were individual-level infection status for each STH type (positive / negative) and intensity of infection in eggs per gram (epg).

\section{Variables}

Individual factors (including age, gender, history of deworming during the past year and shoe wearing behavior), household factors (including highest educational level achieved, head of household occupation, household asset index, urbanization), water sanitation and hygiene (WASH) factors (household water service, household sanitation, household hand washing facility) and environmental factors (elevation, soil sand fraction, soil acidity at average depth $(0-5-15 \mathrm{~cm})$, MODIS daytime land surface temperature mean for 2018 ( $\left.{ }^{\circ} \mathrm{Celsius}\right)$, MODIS . Inanced Vegetation Index (EVI) mean for 2018, MODIS normalized difference vegetation index (NDVI) mean for 2018, aridity index) were collected or constructed based on existing data.

Water, Sanitation and Hygiene variables: Water sources and sanitation facilities reported were grouped and categorized according to the 2017 WHO/UNICEF Joint Monitoring Program (JMP) methodology (none, improved, unimproved, limited or basic). (17) Improved drinking water sources are those that have the potential to deliver safe water by nature of their design and construction, while improved sanitation facilities are those designed to hygienically separate excreta from human contact. (18) Distance to the closest water source and sharing status for sanitation were also collected.

Asset index: An asset index was compiled using principal components analysis. The procedure described by the Demographics and Health Survey (Steps to constructing the new DHS Wealth Index)(19) was followed, but factors associated with STH transmission (crowding [residents/room], WASH variables included in the risk factors analysis, and flooring materials) were excluded as they were evaluated separately in the model.

Environmental variables: We examined the association of the following environmental and sociodemographic factors with STH infection: mean enhanced vegetation index 
and land surface temperature during the study period; elevation; aridity; soil acidity and sand content; and population density. These environmental, topographical, and sociodemographic measures were extracted for each household using point-based extraction using ArcGIS 10.3 (Environmental Systems Research Institute Inc., Redlands, CA, USA). Data sources and methods have been described previously (20). Estimates of population density were obtained by calculating the number of individuals living within $1 \mathrm{~km}^{2}$ buffer around each household, which was used to classify areas as high, medium or low population density. Continuous variables were categorized by tertiles for analysis.

\section{Descriptive statistics}

Categorical variables were described using proportions and $95 \%$ confidence intervals, and the continuous variables were described by the median and interquartile ranges. To compare proportions, we used the Chi-square; and Cuzick trend tests. Continuous variables were compared using the Student $I_{-}$-test and analysis of variance (ANOVA). For each STH species we determined the cluster level prevalence (proportion of individuals infected in the cluster) and cluster level arithmetic mean of individual's egg density per gram of feces. We plotted the cluster level mean egg density against the cluster level prevalence and assessed the strength of the linear relationship using Pearson's correlation coefficient test. Descriptive statistics were generated using Stata® 14.0 (Stata Corp, College Station, Texas).

\section{Factors associated with STH infection}

Factors associated with presence and intensity of baseline infection with each STH species were identified using mixed effects models with random effects at the household and cluster levels and exchangeable correlation matrix. For binary infection status, mixed effects logistic regression was used, while for intensity of infection negative binomial mixed effects regression was used.

For the negative binomial regression, the output was the infection intensity ratio (IIR): $\mathrm{IIR}=e^{\beta}=e^{\left[\log \left(\mu_{\mathrm{x} 0+1}\right)-\log \left(\mu_{\mathrm{x} 0}\right)\right]}=e^{\left[\log \left(\mu_{\mathrm{x} 0+1} / \mu_{\mathrm{x} 0}\right)\right]}$

where $\beta$ is the regression coefficient, $\mu$ is the expected intensity of infection (epg) and the subscripts represent where the predictor variable, say $x$, is evaluated at $x_{0}$ and $x_{0+1}$ 
199 (implying a one unit change in the predictor variable $\mathrm{x}$ ). The IIR are interpreted as the 200 ratio of expected intensity of infection for a one unit increase in the predictor variable given the other variables are held constant in the model.

202

All models were adjusted for age and sex. Groups of socio-economic status indicators, environmental factors and WASH factors hypothesized to be associated with infection were proposed a priori in the multivariable analysis. For groups of indicators with similar variables, the factor from each group with the lowest Akaike Information Criterion (AIC) in univariate analyses was selected for inclusion in the multivariable model. Models were further simplified by backward stepwise elimination until AIC was no longer further reduced in the adjusted model.

Random effects predicted by the fully adjusted model were compared to those predicted by a model containing only age and sex and the proportion of clustering explained by the explanatory variables was quantified.

\section{Ethics statement}

Ethical approval of the DeWorm3 trial protocol was obtained both from the Human Subjects Division at the University of Washington and the National Ethics Committee for Health Research of Benin- (CNERS ethical clearance reference No: 0022017/MS/DC/SGM/DFR/CNERS-Ministry of Health, Benin). The trial was registered at Clinical Trials.gov NCT03014167. Written consent was obtained from each participant (or participants' parents, when participants were under 18 years of age). For children aged 1-6 years old, verbal assent was obtained and for adolescents aged 7-17 years written assent was obtained. Data were collected electronically using password protected smartphones and was stored in datasets. Although WHO guidelines do not recommend MDA for adults, following the stool analysis any adults ( $\geq 15$ years of age) in control clusters presenting moderate to heavy intensity STH infection according to WHO definitions (21) or requiring treatment according to local guidelines, were treated with albendazole by study staff.

\section{Results}


Based on the census data, 11,979 individuals were selected for participation in three consecutive stages (Stage 1: $n=5,979$; Stage 2: $n=3,000$; Stage 3: $n=3,000$ ), with the goal to reach 150 individuals in each cluster: 30 PSAC, 30 SAC and 90 adults. Characteristics of the longitudinal monitoring cohort (LMC) population in comparison to censused population of the DeWorm3 site are presented in Table $1_{2}$ and Fig 1 presents the study flow chart. Individuals selected were listed as living in 9,265 households from which 8,741 were located and visited. In those households 7,045 individuals were present, among whom 6,814 consented to participate in the LMC cohort. Stool samples were collected from 6,153 individuals. The most common reasons for stool samples not being collected were (i) no sample visit documented (319), (ii) sample could not be collected after $\beta_{1}$ visits $(n=111)$, (ii) refusal to provide sample $(\mathrm{n}=231)$. As no documented survey could be verified for 14 individuals, KatoKatz tests performed were confirmed for 6,139 samples comprising 1,184 PSAC (98.7\% of 1,200 expected), 1,335 SAC (>100\% of 1,200 expected), and 3,620 adults (>100\% of 3,600 expected). In total 6,139 tests $\bar{d} \mathrm{~d}$ two slides read by laboratory technicians. A random subset of Kato-Katz tests, was selected for reading by the supervisor and compared against the original readings for quality assurance.

\section{Prevalence of STH}

Among the 6139 individuals tested by Kato-Katz, STH infections of any type were found in 324 (5.3\%), 199 (3.2\%) due to hookworm spp. and 126 (2.0\%) due to Ascaris. Trichuris was found in just $5(0.1 \%)$ individuals (Table 2$)$. Six individuals were coinfected with hookworm and Ascaris. Due to the small number of Trichuris infections, only analyses focused on hookworm-spp. and Ascaris are presented. Among all infections, 258 (79.7\%) were light-intensity, 54 (16.7\%) moderate-intensity and 12 $(3.7 \%)$ heavy intensity infections. Hookworm spp. were more prevalent in adults than in SAC or PSAC (4.4\% versus $2 \%$ versus $1 \%$ respectively, $\left.\mathrm{Chi}^{2}, \mathrm{p}<0.001\right)$. SAC were more frequently infected with Ascaris compared to PSAC or adults (3\% versus $2 \%$ versus $1.7 \%$ respectively, $\mathrm{Chi}^{2}, \mathrm{p}=0.02$ ) (Fig 2 ). A higher proportion of males than females was infected with hookworm spp. (4\% versus $2.6 \% ; \mathrm{p}=0.002)$ and Ascaris 260 (2.6\% versus $1.6 \% ; p=0.004)$. 
The median egg density for hookworm spp. was 108 eggs per gram (epg) (IQR: 48312; range: 12-12,960), 3,840 epg for Ascaris (IQR: 312-15,180; range: 12-135,084) and $120 \mathrm{epg}$ for Trichuris (IQR: 60-468; range: 36-20,124). The intensity of infection was similar in all age groups for hookworm spp. (ANOVA, $p=0.22$ ), with a median egg density of 264 epg (IQR: 36-384; range: 12-3,048) in PSAC, 96 epg (IQR: 24-312; range: 12-11,100) in SAC and 108 epg (IQR: 48-288; range: 12-12,960) in adults. We found a difference in intensity of infection with Ascaris between age-groups (ANOVA, $p=0.005)$, this difference was between $S A C$ and adults (Bonferroni, $p=0.004$ ). Median egg densities were 6,972 epg for PSAC (IQR: 264-26292; range: 12-60000), 7,848 epg for SAC (IQR: 3,714-25,314; range: 84-56,412) and 780 epg for adults (IQR: 36-8,772; range: 12-135084).

Moderate to heavy intensity (MHI) infections were found in 66/6,139 individuals overall (1.1\%) amongst whom 10 (0.2\%) MHI with hookworm spp., 55 (0.9\%) MHI with Ascaris and $1(<0.1 \%) \mathrm{MHI}$ with Trichuris (Table 2). The burden of MHI was greatest in SAC with $2.1 \%(25 / 1,184)$ prevalence of MHI of Ascaris (Table S1). 68.2\% (45/66) of MHI were found in males (Table S2). MHI were distributed in 15/40 clusters. MHI with hookworm spp. were present in 7/40 clusters, MHI with Ascaris in 7/40 clusters and $\mathrm{MHI}$ with Trichuris in 1 cluster. There were two clusters showing a particularly high burden of Ascaris, with respectively 19 (12.7\%) and 30 (20\%) individuals with MHI with Ascaris.

\section{Age- and sex-related prevalence and intensity of STH infection (hookworm and Ascaris)}

Figs 3 and 4 show the age-infection profile for hookworm spp. and Ascaris, respectively. The prevalence of hookworm spp. increased with age in both sexes. The prevalence was similar in males and females among PSAC and SAC but in adults, the prevalence in males was higher than in females except for 50-60 year olds, in whom females were more frequently infected. The intensity of hookworm infection was similar in males and females regardless of age, and was higher in adults than in children. The prevalence of Ascaris infection was similar in males and females across all ages, with the period of adolescence and early adulthood (between 10 and 18 years old) corresponding to the period with highest prevalence of Ascaris infection in males and 
the lowest in females (6\% for males versus $1 \%$ for females). Intensity of Ascaris infection followed the same profile as prevalence in both sexes.

\section{Community-level correlation between intensity and prevalence of STH infection}

We found a positive linear relationship between STH infection prevalence and the intensity of infection at cluster level in our study population (Fig 5). This correlation was strong for both hookworm spp. $(\rho=0.73, p<0.0001)$ and Ascaris $(\rho=0.98, p<0.0001)$.

\section{Factors associated with hookworm infection}

The results of univariate analyses of factors associated with hookworm infection prevalence are presented in Table S2. Here, the results of multivariable analyses-are presented_(Table 3).

At the individual level, PSAC and SAC were significantly less likely to be infected with hookworm spp. than adults $(\mathrm{aOR}=0.21,95 \% \mathrm{Cl} 0.10-0.44, \mathrm{p}<0.001$ and $\mathrm{aOR}=0.49$, $95 \% \mathrm{Cl} 0.29-0.83, p=0.008$, respectively). Females were also significantly less likely to be infected than males $(\mathrm{aOR}=0.56,95 \% \mathrm{Cl} 0.38-0.83, \mathrm{p}=0.004)$. Individuals who reported a history of deworming during the past year were significantly less likely to be infected $(\mathrm{aOR}=0.45,95 \% \mathrm{Cl} 0.27-0.75, \mathrm{p}<0.002)$.

Among household factors, the household asset index, a proxy measure for family wealth, showed that individuals in the poorest households had a significantly higher odds of infection than the richest ( $5^{\text {th }}$ quintile) with a significant dose-response effect (Cuzick test of trend, $p<0.001$ ), (First quintile: $a O R=5.03,95 \% \mathrm{Cl} 2.10-12.01, p<0.001$, $2^{\text {nd }}$ quintile $\mathrm{aOR}=3.62,95 \% \mathrm{Cl} 1.51-8.66, \mathrm{p}=0.001$ and $3^{\text {rd }}$ quintile $\mathrm{aOR}=2.51,95 \% \mathrm{Cl}$ 1.05-6.00, $\mathrm{p}=0.02$ ). With respect to occupational exposure, farmers were more likely to be infected with hookworm spp. than others $(a \mathrm{OR}=1.79,95 \% \mathrm{Cl} 1.11-2.90, \mathrm{p}=0.02)$. Individuals living in medium population density settings were more likely to be infected than those living in high density settings, $(\mathrm{aOR}=2.59,95 \% \mathrm{Cl} 1.25-5.40, \mathrm{p}=0.01)$.

Among WASH factors, household sanitation, and especially open defecation ${ }_{\overline{2}}$ was found to be strongly associated with hookworm infection. Individuals using improved 
unshared sanitation facilities had half the odds of hookworm infection compared to those defecating outdoors ( $\mathrm{aOR}=0.48,0.24-0.98, \mathrm{p}=0.04)$.

\section{= Factors associated with hookworm infection intensity}

Children had a significantly lower intensity of hookworm infection as compared to adults (PSAC: adjusted IIR=0.10,95\%Cl 0.03-0.31, $p<0.001$; SAC: adjusted IIR=0.29, $95 \% \mathrm{Cl} 0.12-0.72, \mathrm{p}=0.01$. Females had significantly lower intensity infections than males (adjusted IIR $=0.32,95 \% \mathrm{Cl} 0.16-0.64, \mathrm{p}=0.001$ ), as did individuals dewormed the year before (adjusted IIR=0.20,95\% Cl 0.08-0.48, $p<0.001$ ). (Table 3 ).

At the household level, less educated people (those with no education, primary school or secondary school) had higher intensity infections with hookworm spp. compared to those with university level education (adjusted IIR=40.13, 95\% $\mathrm{Cl} 2.47-652.77, \mathrm{p}=0.01$; adjusted IIR=30.92, 95\% Cl 1.86-513.88, $\mathrm{p}=0.02$; adjusted IIR=19.34, 95\% $\mathrm{Cl} 1.21-$ 308.81, $p=0.04$, respectively). Being a farmer, living in a house with natural floor material versus man-made floor material, and living in a peri-urban setting were also all factors found to be associated with a significantly increased intensity of hookworm infections (farmer: adjusted IIR=3.94, 95\% $\mathrm{Cl} 1.67-9.27, \mathrm{p}=0.002$; natural floor material: adjusted IIR=0.23, $95 \% \mathrm{Cl} 0.05-1.03, \mathrm{p}=0.06$; peri-urban settings: adjusted IIR=6.18, 95\% Cl $1.82-20.90, p=0.003)$.

Access to unimproved water available more than 30 minutes away from the house was associated with significantly higher intensity hookworm infection (adjusted IIR $=13.47$, $95 \% \mathrm{Cl} 1.62-111.55 ; \mathrm{p}=0.02$ ) compared to improved water available less than 30 minutes from the house. Compared to open defecation behavior, using an improved and unshared toilet was associated with significantly lower intensity hookworm infections (adjusted IIR=0.23, 95\% $0.07-0.70, p=0.01$ ). No environmental factor was found to be associated with intensity of hookworm infections in multivariable analyses. 
Factors associated with Ascaris infection prevalence.

Among the individual factors assessed, SAC (5-14 years) were significantly more likely to be infected with Ascaris than adults $(\mathrm{aOR}=2.0,95 \% \mathrm{Cl} 1.1-3.6, \mathrm{p}=0.01)$. However, no difference in odds of infection was found between PSAC and adults. Female individuals were less likely to be infected with Ascaris than males $(\mathrm{aOR}=0.5,95 \% \mathrm{Cl}$ $0.3-0.9, p=0.02$ ).

Amongst environmental factors, low soil acidity was significantly associated with increased odds of Ascaris infection compared to the highest soil acidity (aOR=4.8, $95 \% \mathrm{Cl} 1.8-13.1, \mathrm{p}=0.002)$. Moderate $\left[29.6-31.9^{\circ} \mathrm{C}\right]$ and high $\left[31.9 ; 32.8^{\circ} \mathrm{C}\right]$ daytime land surface temperatures were associated with lower odds of infection with Ascaris compared to lower temperatures $\left[26.2-29.6^{\circ} \mathrm{C}[(\mathrm{aOR}=0.12,95 \% \mathrm{Cl} 0.03-0.44, \mathrm{p}=0.001\right.$; and $\mathrm{aOR}=0.17,95 \% \mathrm{Cl} 0.03-0.91, \mathrm{p}=0.04$ respectively). The summary of the multivariable analysis with Ascaris is presented in Table 4.

\section{Intra-Class Correlation statistics for hookworm and Ascaris} infection prevalence.

Comparison of the Intra-Class Correlation values between models containing only age and sex (model 1) and the fully adjusted multivariable final model with all the fixed effect covariables (model 2) showed decreased ICC values in the fully adjusted model, considering either level-3 ICC at the cluster level or level-2 ICC at the householdwithin-cluster level (Table S4).

When only adjusting for age and sex, the prevalence of hookworm infection was correlated between individuals within the same cluster ( $I C C=0.16,95 \% \mathrm{Cl} 0.10-0.26$ ), and this correlation increased significantly between individuals within the same household and cluster level (ICC=0.58, 95\%Cl 0.40-0.74). Prevalence of Ascaris infection was moderately correlated within the same cluster (ICC $=0.54,95 \% \mathrm{Cl} 0.34$ 0.73 ), with a small increase within the same household and cluster level (ICC $=0.60$, $95 \% \mathrm{Cl}$ 0.26-0.76). In this model, household and cluster random effects compose approximately $58 \%$ and $60 \%$ of the total residual variance for hookworm spp. and Ascaris infection prevalence, respectively. 
In the fully adjusted multivariable final model, $\overline{\bar{N}}$; found a correlation of hookworm infection prevalence within the same cluster (ICC=0.03, 95\% $\mathrm{Cl} 0.01-0.10)$, although this correlation increased within the same household and cluster level (ICC=0.39, $95 \% \mathrm{Cl}$ 0.17-0.65). Ascaris infection prevalence was moderately correlated between individuals within the same cluster $(\mathrm{ICC}=0.42,95 \% \mathrm{Cl} 0.23-0.64)$, and this correlation increased slightly within the same household and cluster level (ICC=0.51, 95\% CI 0.260.76). We estimated that household and cluster random effects compose approximately $39 \%$ and $51 \%$ of the total residual variance of hookworm and Ascaris infection prevalence, respectively, in the fully adjusted model.

\section{Discussion}

We observed a relatively low prevalence of STH in this region of Benin. Hookworm spp. were the most prevalent infections, and were more prevalent in adults, while Ascaris was more prevalent in children. Females were generally less infected than males across all ages. Females, children, those dewormed during the previous year and those using improved unshared sanitation facilities had lower odds of hookworm infections, while being a farmer, living in peri-urban settings versus urban and being poor was associated with a higher odds of hookworm infection. In addition to those factors, the intensity of hookworm infection was also decreased if an improved water source was available at less than 30 minutes distance.

Since 2013, the Ministry of Health in Benin has focused its efforts on developing and implementing strategies for the control of five NTDs considered to be of highest priority, namely trachoma, onchocerciasis, lymphatic filariasis, schistosomiasis and soiltransmitted helminths. Those efforts were bolstered markedly through the ENVISION program (22), a USAID-funded initiative that ran from 2013 through 2019 in Benin. A nationwide STH prevalence survey was completed in 2015, that reported $20 \%$ prevalence (13) in school-aged children in Comé district. Following that national mapping effort, 3 -rounds of school-based MDA with albendazole were undertaken according to the recommendations of WHO, i.e. primarily targeting school-age (SAC) and pre-school age children (PSAC) for either once or twice yearly treatment as a function of the estimated prevalence of infection in any given district. (23) Coverage of 
SAC with school MDA between 2015 and 2017 was estimated between 59\% and 83\%. Albendazole and/or Mebendazole are also distributed in health facilities and to pregnant women during routine antenatal care starting from the $2^{\text {nd }}$ trimester of pregnancy. (24) In the context-described, we sought to better understand patterns of STH infection in order to move towards the elimination STH as a public health problem, by reaching a prevalence of STH less than 1\%, as prescribed by the WHO Neglected Tropical Disease (NTD) Roadmap and London Declaration on NTD. $(10,23)$

When focusing on the at-risk population of SAC, the prevalence of STH infection found in the current study is lower than that reported in the same district using the same diagnostic technique in 2015 during the national mapping exercise (5.2\% versus $20.0 \%$ respectively, $p<0.001)$. Il at survey was conducted with a total of 250 stool samples from SAC collected from schools located in 5 rural villages. (13) The prevalence of infections with Ascaris (3.0\% versus $15.6 \%$ respectively, $\mathrm{p}<0.001)$ or Trichuris $(0.15 \%$ in 2018 versus $4.8 \%$ in 2015, $\mathrm{p}<0.001$ ) decreased while the decrease in prevalence of hookworm spp. in SAC was less marked (2.0\% in 2018 versus 4.0\% in 2015, $p=0.054$ ) compared to the findings of the national STH mapping 3 years earlier. (13) The decline in STH prevalence in the study area might be related to differences in sampling, as the current study was conducted in the community instead of in-schools, with more than 6,000 stools randomly selected from three age groups (PSAC, SAC and adults). (11) STH prevalence estimates can vary depending on the sampling strategies used. (25) The reasons for the observed variations of prevalence between hookworm spp. and other STH species in SAC could also be that STH rate of reinfection post-treatment varies across species, with a faster reinfection with Ascaris than hookworm spp. systematic review of helminth reinfection at 3, 6, and 12 months $(95 \% \mathrm{Cl})$, after drug treatment shows that Ascaris prevalence reached 26\% (16-43\%), 68\% (60-76\%) and 94\% (88-100\%) of pretreatment levels, respectively and for hookworm spp., 30\% (26$34 \%), 55 \%(34-87 \%)$, and $57 \%(49-67 \%)$. (26) These results may also be partly explained by the fact that the current STH program does not include adults. The suggestion that hookworm spp. prevalence only decreased slightly between 2015 and 2018, may be due to the persistent untreated adult reservoir in which hookworm spp. are most common. Data from several worm expulsion studies show that the proportion of hookworms harbored by adults ranged from 70 to $85 \%,(27-32)$ and a reinfectioninfection study in Indonesia show that adults have higher reinfection rates with 
hookworm spp. than children. (33) Children cleared of hookworms through annual school de-worming could easily be re-infected at home through contact with adult members of their households.

Hookworm prevalence was higher in adults while Ascaris prevalence was higher in children. One explanation of these findings might be helminth species transmission modes. (34) The three species of STH (A. lumbricoides, T. trichiura, hookworm spp.) have relatively similar cycles involving the presence of adult worms in the intestine $\overline{\bar{z}}_{\bar{z}}$ however the main mode of transmission of Ascaris and Trichuris is through contaminated food and water (parasite egg ingestion) whereas hookworm spp. are mainly transmitted by skin penetration, although they can be transmitted by ingestion. $(35,36)$ The eggs of Ascaris and Trichuris are found in soil contaminated by human feces or in uncooked food contaminated by soil containing eggs of the worm. A person becomes infected after accidentally swallowing the fertile eggs. Children may be more likely to be infected with Ascaris because they are more likely to put their contaminated fingers in their mouths after playing in contaminated soil. (37) Unlike Ascaris infection, which declines in prevalence with age, hookworm infects all ages throughout life with prevalence increasing in adults. (27)

Community-level prevalence and the arithmetic mean of infection intensity were significantly correlated for all STH infections in our study, with a strong prevalenceintensity correlation for infection with hookworm and Ascaris. Similar trends were recently found in Kenya for hookworm spp. and Trichuris. (20) At the individual level, prevalence and intensity of hookworm infection followed the same trend. Markers of poverty and exposure to environmental sources of STH infection, including being a farmer, lack of improved or private sanitation facilities, low income, poor access to water, no or limited education, or living in a house with natural floor material were all associated with a higher prevalence or intensity of hookworm infection. These findings are linked with the mode of hookworm spp. transmission, which is direct either by ingestion (for $A$. duodenale) or by skin penetration (both $N$. americanus and $A$. duodenale) of infective larval stages living in the soil. $(38,39)$ These findings are consistent with the results of a recent study in Kenya where there was a strong association between hookworm infection prevalence and intensity and socio-economic status, with those in the poorest households having the heaviest infections and highest prevalence, and wealthier individuals having the lightest intensity and reduced odds of 
infection. (20) Globally, a negative correlation between hookworm infections and income level is demonstrated in cross-country comparisons. (40-42) Moderate population density, corresponding to a peri-urban environment, was also associated with both high prevalence and heavy intensity of hookworm infection when compared to the higher population density observed in urban environments. (43)

Although we found no association between hookworm prevalence and water source, quality of water seems to affect intensity of hookworm infection. Heavier intensity infections were found in participants with access only to unimproved water, such as unprotected wells, unprotected springs and surface water available at more than 30 minutes from the house. In a school survey in Togo, unimproved drinking water was associated with higher odds and intensity of hookworm. (44) Malaysian children with access to piped water were less infected with hookworm. (45) However, other researchers have found no statistically significant associations between piped water access and hookworm infection $(46,47)$. We did not find any association between WASH variables and either prevalence or intensity of Ascaris infection. However, there is evidence that integrated water, sanitation and hand hygiene intervention, treatment of water with chlorine (48), drinking piped water, as well as hand washing before eating and after defecating reduce the odds of Ascaris infection. (49)

This study had a number of strengths, including the large population size, completeness and quality of data and the high level of quality control for Kato-Katz diagnosis, with double reading by the lab technicians of the whole sample with an additional control of a subset of samples by a senior skilled parasitologist. However, this study does has some limitations. First, the STH prevalence in Come hides interand intra-specific variations between clusters that will be developed in further analyses once the parent study is unblinded and we have access to those results. It was also necessary to use a staged approach to sampling in order achieve the required number of participants who consented to participate in the longitudinal monitoring cohort, which may have limited its representativeness. Another possible limitation is the reliance on Kato-Katz to detect STH. Kato-Katz is poorly sensitive, particularly for low intensity infections and can be affected by storage and processing time and methods. $(50,51)$ 
517 Future analyses using qPCR-based methods will allow for more sensitive detection of of STH in stool.

\section{Conclusion}

This analysis of the DeWorm3 baseline study data shows that hookworm spp. are-the predominant STH in Comé, with a persistent reservoir in adults. This infection reservoir is not addressed by current school-based MDA control measures. These data suggest that community-based MDA may help eliminate STH as a public health problem. Improved unshared sanitation and access to improved water sources are associated with lower prevalence and/or intensity of hookworm infection. Programmatic efforts should pay particular attention to farmers and populations living in poverty in urban, rural and peri-urban environments. The DeWorm3 trial (2017-2022) will determine the feasibility of STH transmission interruption through community-wide MDA given twicea-year for three years in this setting, and combined, with these results will inform programmatic and policy decisions to improve efforts to eliminate morbidity and infection due to these pervasive infections.

\section{Declaration of competing interest:}

The DeWorm3 study is funded by Bill and Melinda Gates foundation. EA is a PhD candidate at the University of Paris. His research is funded by DeWorm3 as a staff member of the Benin coordinating team, and by the French Research Institute for Sustainable Development (IRD) through the International Mixed Laboratory LMI CONS_HELM (helminth infections: treatments and consequences on health and development in the South).

\section{Authors' contribution:}


545 KHA designed the article statistical methodology and reviewed the analysis and entire 546 article draft,

$547 \mathrm{PH}$ add inputs to the statistical analysis,

$548 \mathrm{KHA}, \mathrm{ARM}, \mathrm{JLW}, \mathrm{TJL}, \mathrm{SG}$, designed the Deworm3 clinical trial

549 EFGAA, MA, KHA, AJFL, MI, AG, JLW reviewed the article draft and the final version.

552 Funding: Bill and Melinda Gates foundation

553 Sponsor: Natural History Museum, United Kingdom

\section{Collaborators:}

555 Bill and Melinda Gates Foundation

556 University of Washington

557 Imperial College London

558 London School of Hygiene and Tropical Medicine

559 Institut de Recherche Clinique du Bénin

560 Institut de Recherche pour le Développement

561

562

563

\section{Acknowledgements}

565 Thanks to Kate Halliday for sharing a Stata code to illustrate the age-infection profile 566 for hookworm and Ascaris. We are particularly grateful to William Oswald, David 567 Kennedy and Mira Emmanuel-Fabula for their invaluable contributions to data 568 collection and quality.

569 We thank Dr Batcho and his staff of the National NTD Program (PNLMT), and finally 570 we are grateful to all Comé district population, administrative and health authorities for 571 their support in the success of this study. 


\section{References}

579

1. Hotez $P$, Ottesen $E$, Fenwick $A$, Molyneux $D$. The neglected tropical diseases: the ancient afflictions of stigma and poverty and the prospects for their control and elimination. Adv Exp Med Biol. 2006;582:23-33.

2. Soil-transmitted helminth infections [Internet]. [cited 2019 Nov 3]. Available from: https://www.who.int/news-room/fact-sheets/detail/soil-transmitted-helminth-infections

3. WHO | 12th meeting of the Strategic and Technical Advisory Group for Neglected Tropical Diseases [Internet]. [cited 2020 Apr 4]. Available from: https://www.who.int/neglected_diseases/events/twelfth_stag/en/

4. Soil-transmitted helminthiases : eliminating as public health problem soil-transmitted helminthiases in children : progress report 2001-2010 and strategic plan 2011-2020 [Internet]. [cited 2020 Apr 24]. Available from: https://apps.who.int/iris/handle/10665/44804

591

592

593

594

595

596

597

598

599

600

601

602

5. Mpairwe $\mathrm{H}$, Tweyongyere $\mathrm{R}$, Elliott A. Pregnancy and helminth infections. Parasite Immunol. 2014 Aug;36(8):328-37.

6. Mireku MO, Boivin MJ, Davidson LL, Ouédraogo S, Koura GK, Alao MJ, et al. Impact of Helminth Infection during Pregnancy on Cognitive and Motor Functions of One-Year-Old Children. Kang G, editor. PLoS Negl Trop Dis. 2015 Mar 10;9(3):e0003463.

7. Gall S, Müller I, Walter C, Seelig H, Steenkamp L, Pühse U, et al. Associations between selective attention and soil-transmitted helminth infections, socioeconomic status, and physical fitness in disadvantaged children in Port Elizabeth, South Africa: An observational study. Flisser A, editor. PLoS NegI Trop Dis. 2017 May 8;11(5):e0005573.

8. Larocque R, Casapia M, Gotuzzo E, Gyorkos TW. RELATIONSHIP BETWEEN INTENSITY OF SOILTRANSMITTED HELMINTH INFECTIONS AND ANEMIA DURING PREGNANCY. Am J Trop Med Hyg. 2005 Oct 1;73(4):783-9. 
9. Welch VA, Ghogomu E, Hossain A, Awasthi S, Bhutta ZA, Cumberbatch C, et al. Mass deworming to improve developmental health and wellbeing of children in low-income and middle-income countries: a systematic review and network meta-analysis. Lancet Glob Health. 2018 May 22;5:e40-50.

10. London Declaration on Neglected Tropical Diseases | Uniting to Combat NTDs [Internet]. [cited 2020 Apr 5]. Available from: https://unitingtocombatntds.org/london-declaration-neglectedtropical-diseases/

11. Ásbjörnsdóttir KH, Ajjampur SSR, Anderson RM, Bailey R, Gardiner I, Halliday KE, et al. Assessing the feasibility of interrupting the transmission of soil-transmitted helminths through mass drug administration: The DeWorm3 cluster randomized trial protocol. Garba A, editor. PLoS Negl Trop Dis. 2018 Jan 18;12(1):e0006166.

12. Boko PM, Ibikounle M, Onzo-Aboki A, Tougoue J-J, Sissinto Y, Batcho W, et al. Schistosomiasis and Soil Transmitted Helminths Distribution in Benin: A Baseline Prevalence Survey in $\mathbf{3 0}$ Districts. Serrano Ferron E, editor. PLOS ONE. 2016 Sep 19;11(9):e0162798.

13. Ibikounlé M, Onzo-Aboki A, Doritchamou J, Tougoué J-J, Boko PM, Savassi BS, et al. Results of the first mapping of soil-transmitted helminths in Benin: Evidence of countrywide hookworm predominance. Aksoy S, editor. PLoS Negl Trop Dis. 2018 Mar 1;12(3):e0006241.

14. Team TDT. Baseline patterns of infection in regions of Benin, Malawi and India seeking to interrupt transmission of soil transmitted helminths (STH) in the DeWorm3 trial. PLoS Negl Trop Dis. 2020 Nov 2;14(11):e0008771.

15. EDS_2012_Rapport_final-11-15-2013.pdf [Internet]. [cited 2020 Apr 5]. Available from: https://www.insae-bj.org/images/docs/insae-statistiques/enquetes-recensements/EDS/20112012/EDS_2012_Rapport_final-11-15-2013.pdf

16. Katz N, Chaves A, Pellegrino J. A simple device for quantitative stool thick-smear technique in Schistosomiasis mansoni. Rev Inst Med Trop Sao Paulo. 1972 Dec;14(6):397-400.

17. Methods | JMP [Internet]. [cited 2020 Oct 4]. Available from: https://washdata.org/monitoring/methods 
19. Shea O. Rutstein, DHS Asset index calculation - Recherche Google [Internet]. [cited 2019 Dec 31]. Available from: https://www.google.bj/search?sxsrf=ACYBGNQVqWgdnooBO2f7bESKoDpxgi_Eig\%3A15778319 86052\&ei=Ms4LXu7pAoeiUsLljKAD\&q=Shea+O.+Rutstein\%2C+DHS+Asset+index+calculation\&o $q=$ Shea+O.+Rutstein\%2C+DHS+Asset+index+calculation\&gs_l=psyab.3..33i160.142205.151213..151495...0.0..0.294.7369.2-31.....0....1..gwswiz.......35i39j33i21.ZigUpaQrJxY\&ved=0ahUKEwjuyqyYuDmAhUHkRQKHUIkAzQQ4dUDCAs\&uact=5

20. Halliday KE, Oswald WE, Mcharo C, Beaumont E, Gichuki PM, Kepha S, et al. Community-level epidemiology of soil-transmitted helminths in the context of school-based deworming: Baseline results of a cluster randomised trial on the coast of Kenya. Garba A, editor. PLoS NegI Trop Dis. 2019 Aug 9;13(8):e0007427.

21. WHO Expert Committee. Prevention and control of schistosomiasis and soil-transmitted helminthiasis. World Health Organ Tech Rep Ser. 2002;912:i-vi, 1-57, back cover.

22. ENVISION | a world free of NTDs [Internet]. [cited 2020 Apr 5]. Available from: http://www.ntdenvision.org/

23. NTD_RoadMap_2012_Fullversion.pdf [Internet]. [cited 2020 Apr 5]. Available from: https://www.who.int/neglected_diseases/NTD_RoadMap_2012_Fullversion.pdf

24. Weltgesundheitsorganisation, editor. Preventive chemotherapy in human helminthiasis: coordinated use of anthelminthic drugs in control interventions ; a manual for health professionals and programme managers. Geneva: World Health Organization; 2006. 62 p.

25. Giardina F, Coffeng LE, Farrell SH, Vegvari C, Werkman M, Truscott JE, et al. Sampling strategies for monitoring and evaluation of morbidity targets for soil-transmitted helminths. Lustigman S, editor. PLoS Negl Trop Dis. 2019 Jun 26;13(6):e0007514.

26. Jia T-W, Melville S, Utzinger J, King $\mathrm{CH}$, Zhou X-N. Soil-transmitted helminth reinfection after drug treatment: a systematic review and meta-analysis. PLoS NegI Trop Dis. 2012 Jan 1;6(5):e1621.

27. Turner HC, Truscott JE, Bettis AA, Shuford KV, Dunn JC, Hollingsworth TD, et al. An economic evaluation of expanding hookworm control strategies to target the whole community. Parasit 
Vectors [Internet]. 2015 Nov 5 [cited 2020 Apr 25];8. Available from: https://www.ncbi.nlm.nih.gov/pmc/articles/PMC4635541/

28. Ye XP, Wu ZX, Sun FH. The population biology and control of Necator americanus in a village community in south-eastern China. Ann Trop Med Parasitol. 1994 Dec;88(6):635-43.

29. Bradley M, Chandiwana SK, Bundy DA, Medley GF. The epidemiology and population biology of Necator americanus infection in a rural community in Zimbabwe. Trans R Soc Trop Med Hyg. $1992 \mathrm{Feb} ; 86(1): 73-6$.

30. Haswell-Elkins MR, Elkins DB, Manjula K, Michael E, Anderson RM. An investigation of hookworm infection and reinfection following mass anthelmintic treatment in the south Indian fishing community of Vairavankuppam. Parasitology. 1988 Jun;96 ( Pt 3):565-77.

31. Pritchard DI, Quinnell RJ, Slater AF, McKean PG, Dale DD, Raiko A, et al. Epidemiology and immunology of Necator americanus infection in a community in Papua New Guinea: humoral responses to excretory-secretory and cuticular collagen antigens. Parasitology. 1990 Apr;100 Pt 2:317-26.

32. Anderson RM, Schad GA. Hookworm burdens and faecal egg counts: an analysis of the biological basis of variation. Trans R Soc Trop Med Hyg. 1985;79(6):812-25.

33. Soeripto N. Reinfection and infection rates of soil-transmitted-helminths in Kemiri Sewu, Yogyakarta, Indonesia. Southeast Asian J Trop Med Public Health. 1991 Jun;22(2):216-21.

34. Truscott JE, Turner HC, Farrell SH, Anderson RM. Soil-Transmitted Helminths: Mathematical Models of Transmission, the Impact of Mass Drug Administration and Transmission Elimination Criteria. Adv Parasitol. 2016;94:133-98.

35. Hookworm. - PubMed - NCBI [Internet]. [cited 2019 Nov 3]. Available from: https://www.ncbi.nlm.nih.gov/pubmed/?term=Banwell+JG\%2C+Schad+GA.+(1978)+Hookworm .+Clin+Gastroenterol.+7\%3A129\%E2\%80\%9356.

36. Prevention C-C for DC and. CDC - Hookworm [Internet]. 2019 [cited 2020 Apr 25]. Available from: https://www.cdc.gov/parasites/hookworm/index.html

37. WHO | Water related diseases [Internet]. WHO. World Health Organization; [cited 2020 Apr 25]. Available from: http://www.who.int/water_sanitation_health/diseasesrisks/diseases/ascariasis/en/ 
689

690

691

692

693

694

695

696

697

698

699

700

701

702

703

704

705

706

707

708

709

710

711

712

713

714

715

716

38. Hoagland KE, Schad GA. Necator americanus and Ancylostoma duodenale: life history parameters and epidemiological implications of two sympatric hookworms of humans. Exp Parasitol. 1978 Feb;44(1):36-49.

39. Banwell JG, Schad GA. Hookworm. Clin Gastroenterol. 1978 Jan;7(1):129-56.

40. de Silva NR, Brooker S, Hotez PJ, Montresor A, Engels D, Savioli L. Soil-transmitted helminth infections: updating the global picture. Trends Parasitol. 2003 Dec 1;19(12):547-51.

41. Brooker S, Bethony J, Hotez PJ. Human Hookworm Infection in the 21st Century. Adv Parasitol. 2004;58:197-288.

42. Fenghua S, Zhongxing W, Yixing Q, Hangqun $C$, Haichou X, Hainan R, et al. Epidemiology of human intestinal nematode infections in Wujiang and Pizhou counties, Jiangsu Province, China. Southeast Asian J Trop Med Public Health. 1998 Sep;29(3):605-10.

43. Yapi RB, Chammartin F, Hürlimann E, Houngbedji CA, N'Dri PB, Silué KD, et al. Bayesian risk profiling of soil-transmitted helminth infections and estimates of preventive chemotherapy for school-aged children in Côte d'Ivoire. Parasit Vectors [Internet]. 2016 Mar 21 [cited 2019 Nov 12];9. Available from: https://www.ncbi.nlm.nih.gov/pmc/articles/PMC4802658/

44. Baker JM, Trinies V, Bronzan RN, Dorkenoo AM, Garn JV, Sognikin S, et al. The associations between water and sanitation and hookworm infection using cross-sectional data from Togo's national deworming program. PLoS Negl Trop Dis [Internet]. 2018 Mar 28 [cited 2019 Nov 12];12(3). Available from: https://www.ncbi.nlm.nih.gov/pmc/articles/PMC5902041/

45. Nasr NA, Al-Mekhlafi HM, Ahmed A, Roslan M, Bulgiba A. Towards an effective control programme of soil-transmitted helminth infections among Orang Asli in rural Malaysia. Part 1: Prevalence and associated key factors. Parasit Vectors. 2013;6(1):27.

46. Cundill B, Alexander N, Bethony JM, Diemert D, Pullan RL, Brooker S. Rates and intensity of reinfection with human helminths after treatment and the influence of individual, household, and environmental factors in a Brazilian community. Parasitology. 2011 Sep;138(11):1406-16.

47. Kounnavong $\mathrm{S}$, Vonglokham $\mathrm{M}$, Houamboun $\mathrm{K}$, Odermatt $\mathrm{P}$, Boupha B. Soil-transmitted Helminth Infections and Risk Factors in Preschool Children in Southern Rural Lao People's Democratic Republic. Trans R Soc Trop Med Hyg. 105(3):160-3. 
48. Pickering AJ, Njenga SM, Steinbaum L, Swarthout J, Lin A, Arnold BF, et al. Effects of single and integrated water, sanitation, handwashing, and nutrition interventions on child soil-transmitted helminth and Giardia infections: A cluster-randomized controlled trial in rural Kenya. PLoS Med [Internet]. 2019 Jun 26 [cited 2019 Nov 12];16(6). Available from:

https://www.ncbi.nlm.nih.gov/pmc/articles/PMC6594579/

49. Strunz EC, Addiss DG, Stocks ME, Ogden S, Utzinger J, Freeman MC. Water, Sanitation, Hygiene, and Soil-Transmitted Helminth Infection: A Systematic Review and Meta-Analysis. PLoS Med [Internet]. 2014 Mar 25 [cited 2020 Jan 10];11(3). Available from: https://www.ncbi.nlm.nih.gov/pmc/articles/PMC3965411/

50. Bärenbold O, Raso G, Coulibaly JT, N'Goran EK, Utzinger J, Vounatsou P. Estimating sensitivity of the Kato-Katz technique for the diagnosis of Schistosoma mansoni and hookworm in relation to infection intensity. PLoS NegI Trop Dis [Internet]. 2017 Oct 4 [cited 2020 Oct 24];11(10). Available from: https://www.ncbi.nlm.nih.gov/pmc/articles/PMC5643140/

51. Nikolay B, Brooker SJ, Pullan RL. Sensitivity of diagnostic tests for human soil-transmitted helminth infections: a meta-analysis in the absence of a true gold standard. Int J Parasitol. 2014 Oct 1;44(11):765-74. 
Figure 1: Flow diagram of stool sample collection for Benin site DeWorm3 baseline prevalence survey in Comé

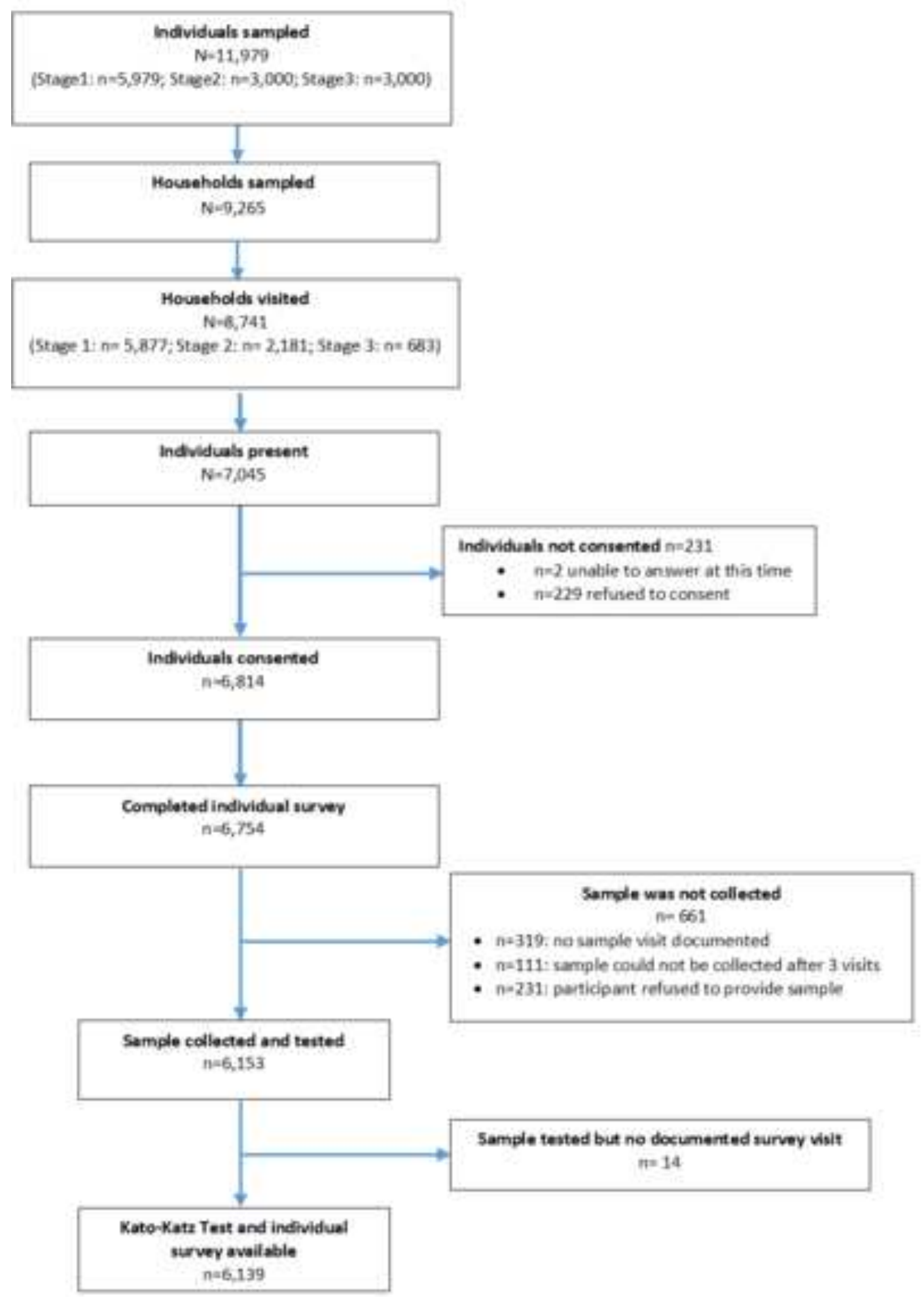

Fig 1: Flow diagram of stod sample collection for Benin site DeWorm3 baseline prevalence survey in Comé 


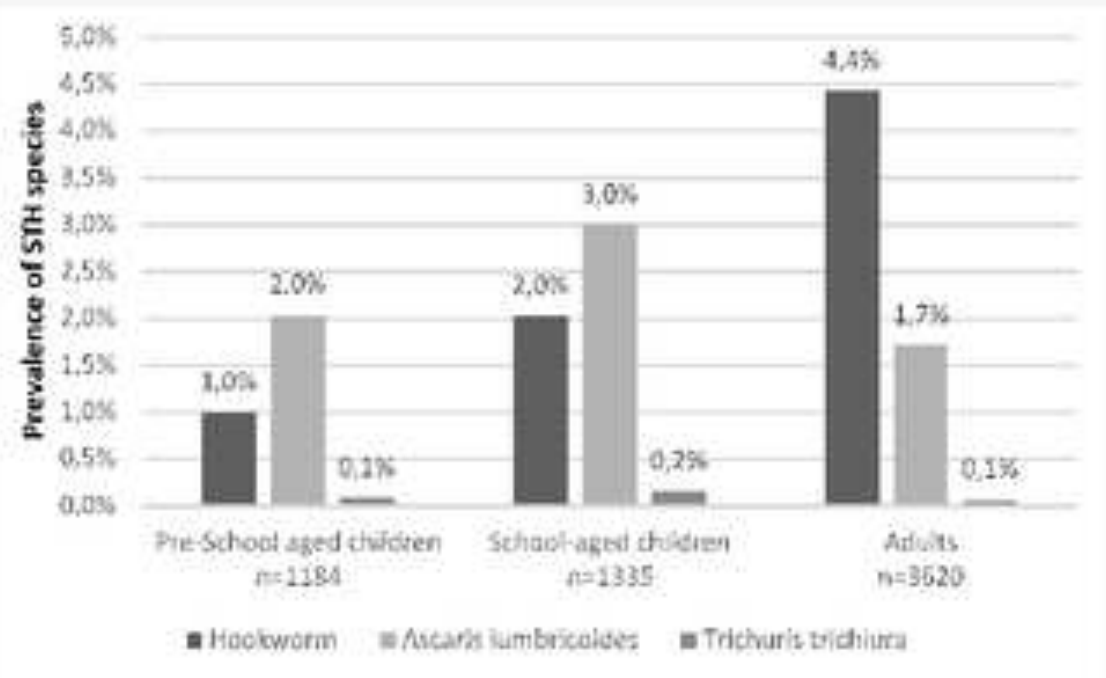

Fig 2: STH unweighted prevalence across age-groups 


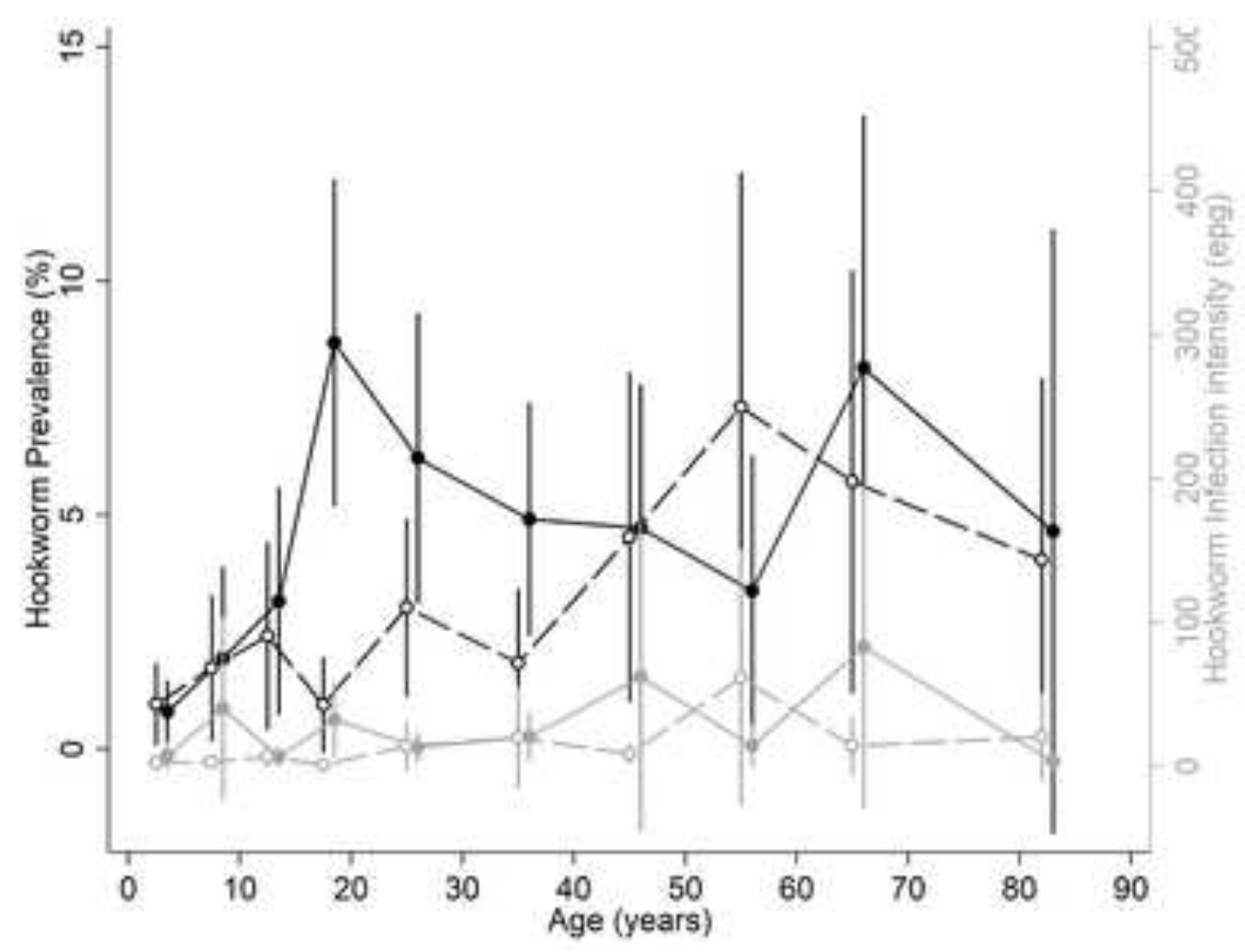

Fig 3. Age-infection profiles for hookworm. (A) Prevalence (black lines) and intensity (grey lines) of hookworm infection by age for males (solid line and circles) and females (dashed lines and empty circles). Vertical bars tepresent confidence intervals. 


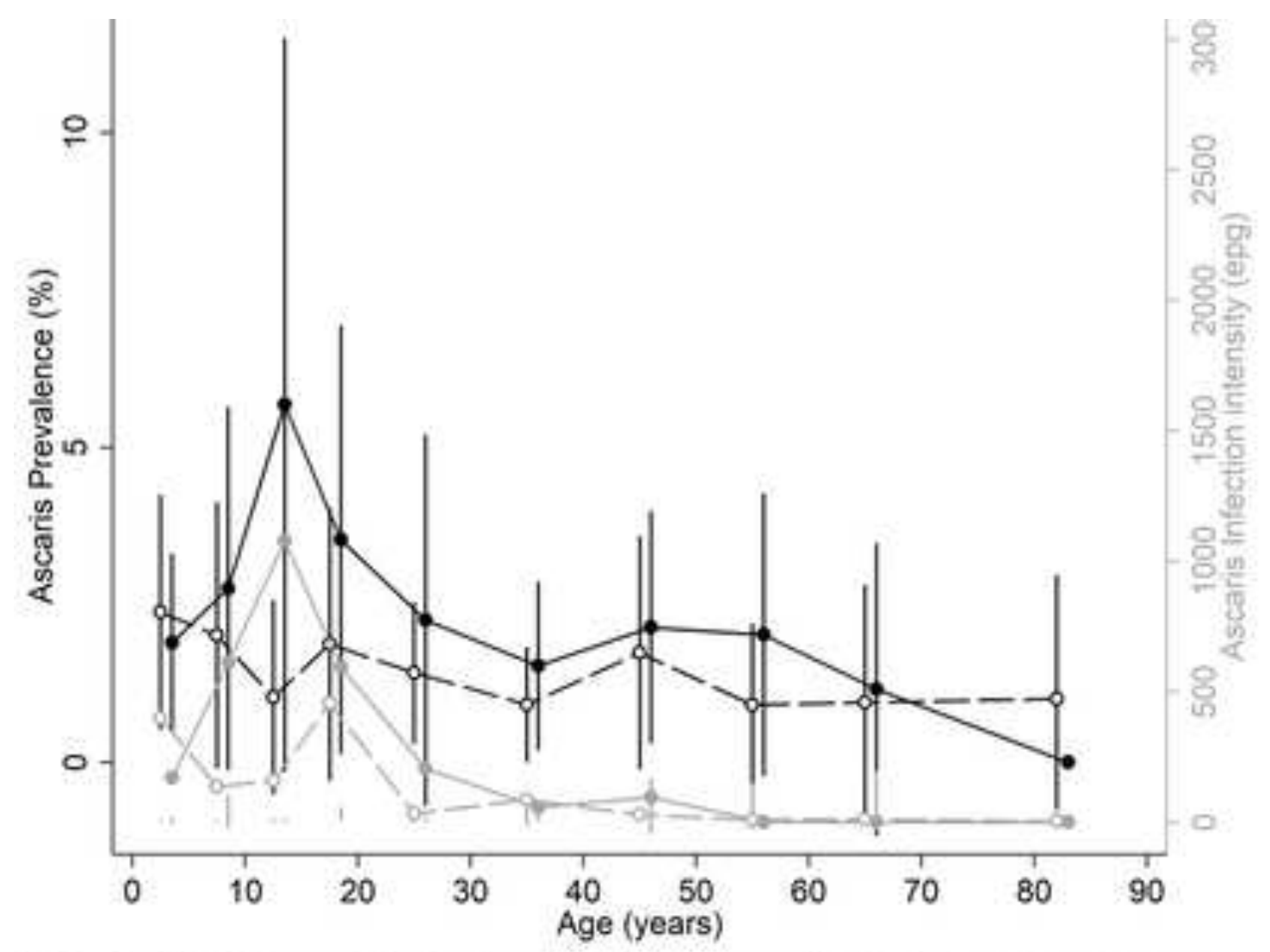

Fig 4. Age-infection proflies for Ascaris. (A) Prevalence (black lines) and intensity (grey lines) of Ascaris infection by age for males (solid line and circles) and females (dashed lines and empty circles). Vertical bars represent confidence intervals. 
Fig 5: Cluster level correlation between prevalence and intensity of hookworm and Ascaris infection in the study population

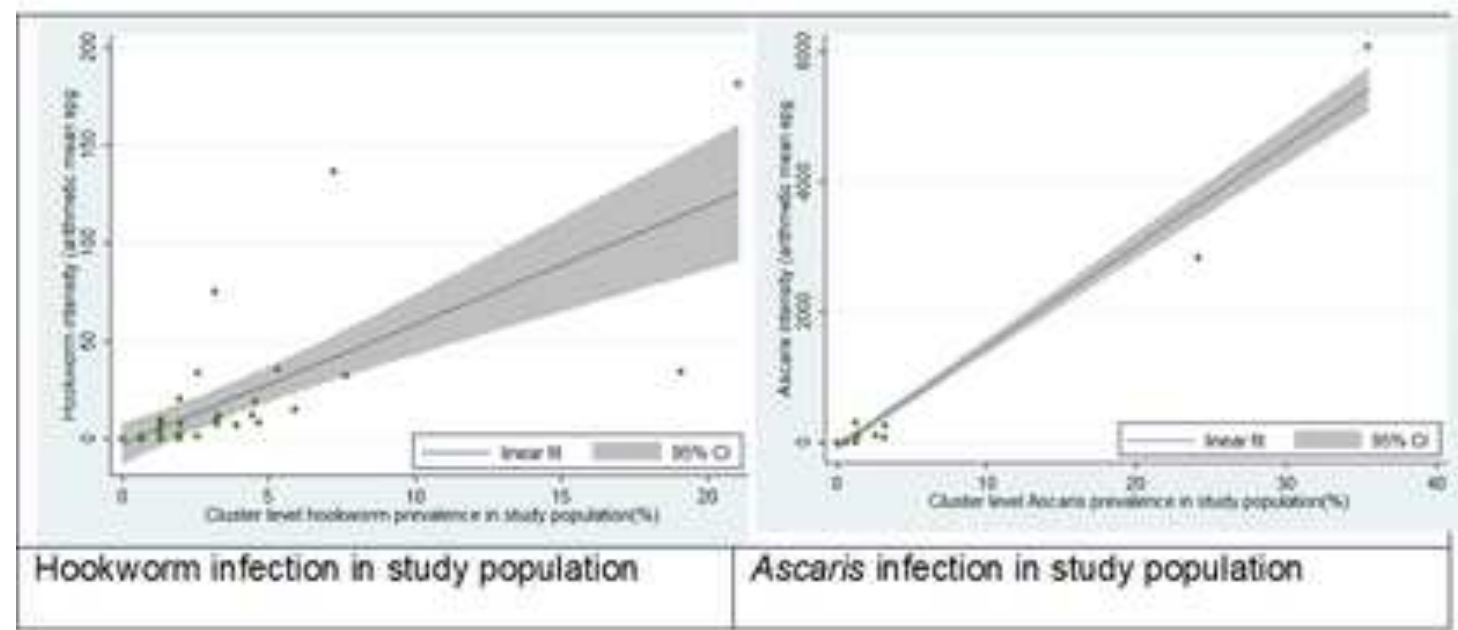

Figure 5: Cluster level correlation between prevalence and intensity of hookworm and Ascaris infection in the study population. ard 
Table 1: Comparison of censused population of the DeWorm3 site and longitudinal monitoring cohort (LMC).

\begin{tabular}{|c|c|c|}
\hline & Census & LMC \\
\hline & $\begin{array}{c}\mathrm{n}(\%) / \\
\text { median (IQR) }\end{array}$ & n (\%) / median (IQR) \\
\hline Study population (consented) & $94,969(83.99)$ & $6,814(96.52)$ \\
\hline \multicolumn{3}{|l|}{ Gender* } \\
\hline - Female & $49,080(51.68)$ & $3,311(53.93)$ \\
\hline - Male & $45,888(48.32)$ & $2,828(46.07)$ \\
\hline \multicolumn{3}{|l|}{ Age distribution* } \\
\hline - Infants $(<1$ years $)$ & $2,616(2.75)$ & - \\
\hline - $\quad$ Preschool-age children (1-4 years) & $11,188(11.78)$ & $1,184(19.29)$ \\
\hline - $\quad$ School age children (5-14 years) & $26,043(27.42)$ & $1,335(21.75)$ \\
\hline Adults (15+ years) & $54,882(57.79)$ & $3,620(58.97)$ \\
\hline \multicolumn{3}{|l|}{ Household characteristics } \\
\hline \multicolumn{3}{|l|}{ Roof materials* } \\
\hline - Natural materials & $5,311(5.59)$ & $349(5.68)$ \\
\hline - Man-made materials & $89,342(94.07)$ & $5,771(94.01)$ \\
\hline \multicolumn{3}{|l|}{ Walls materials } \\
\hline - Natural materials & $22,200(23.38)$ & $1,359(22.14)$ \\
\hline - Man-made materials & $71,258(75.03)$ & $4,665(75.99)$ \\
\hline \multicolumn{3}{|l|}{ Flooring materials } \\
\hline - Natural materials & $16,336(17.20)$ & $950(15.47)$ \\
\hline - Man-made materials & $78,200(82.34)$ & $5,162(84.09)$ \\
\hline \multicolumn{3}{|l|}{$\begin{array}{l}\text { Sources of income } \\
\text {-categories }\end{array}$} \\
\hline Asset Index quintiles & $(\mathrm{n}=24,378$ households) & $(\mathrm{n}=6,139$ individuals $)$ \\
\hline Quintile 1 : range [-2.67;-1.84] & $5,243(21.51)$ & $985(16.04)$ \\
\hline Quintile 2 : range $[-1.84 ;-1.19]$ & $4,620(18.95)$ & $1,043(16.99)$ \\
\hline Quintile 3 : range $[-1.19 ;-0.16]$ & $4,840(19.85)$ & $1,175(19.14)$ \\
\hline Quintile 4 : range $[-0.16 ; 2.00]$ & $4,884(20.03)$ & $1,378(22.45)$ \\
\hline Quintile 5 : range $[2.00 ; 12.04]$ & $4,791(19.65)$ & $1,558(25.38)$ \\
\hline Number of Residents/per Household & $5(4-7)$ & $5(4-7)$ \\
\hline
\end{tabular}


Table 2: Unweighted STH prevalence and intensity of infection by Kato-Katz testing. $\mathrm{N}=6139$

\begin{tabular}{|l|l|l|l|l|}
\hline Kato-Katz Indicator & $\begin{array}{l}\text { Any STH } \\
\text { prevalence } \\
(\%)\end{array}$ & $\begin{array}{l}\text { Hookworm } \\
\text { prevalence } \\
(\%)\end{array}$ & $\begin{array}{l}\text { Ascaris } \\
\text { prevalence } \\
(\%)\end{array}$ & $\begin{array}{l}\text { Trichuris } \\
\text { prevalence } \\
(\%)\end{array}$ \\
\hline \multicolumn{2}{|l}{ UNWEIGHTED ESTIMATES }
\end{tabular}

Unweighted Kato-Katz prevalence: $\mathbf{n}(\%)^{1}$

\begin{tabular}{|l|l|l|l|l|}
\hline Positive & $324(5.3)$ & $199(3.2)$ & $126(2.0)$ & $5(0.1)$ \\
\hline Negative & $5,815(94.7)$ & $5,940(96.8)$ & $6,013(98.0)$ & $6,134(99.9)$ \\
\hline
\end{tabular}

Intensity of infection, among positive Kato-Katz tests: $\mathbf{n}(\%)^{2}$

\begin{tabular}{|l|l|l|l|l|}
\hline Light-intensity & $258(79.6)$ & $189(95.0)$ & $71(56.3)$ & $4(80.0)$ \\
\hline Moderate-intensity & $54(16.7)$. & $4(2.0)$ & $50(39.7)$ & $0(0.0)$ \\
\hline Heavy-intensity & $12(3.7)$ & $6(3.0)$ & $5(4.0)$ & $1(20.0)$ \\
\hline
\end{tabular}

Unweighted prevalence of moderate/heavy intensity infections: $\mathbf{n}(\%)$

\begin{tabular}{|l|l|l|l|}
\hline Moderate- or Heavy- & $66(0.2)$ & $10(0.0)$ & $55(0.9)$
\end{tabular}

intensity infection

${ }^{1}$ Positivity was defined as the presence of eggs on one of two slides read by laboratory technicians.

${ }^{2}$ Light-intensity infections are defined as 1-4,999 epg of faeces for Ascaris infection, 1-999 epg for Trichuris and 1-1,999 epg for Hookworms. Moderate-intensity infections are defined as 5,000-49,999 epg for Ascaris, 1,000-9,999 epg for Trichuris and 2,000-3,999 epg for Hookworms. Heavy-intensity infections are defined as 50,000+ epg for Ascaris, 10,000+ epg for Trichuris and 4,000+ epg for Hookworms. 
Table 3 :Factors associated with the the prevalence and the intensity of hookworm infection in Comé, Bénin : findings from a cross-sectional baseline prevalence survey in the DeWorm3 STH-elimination trial.

\begin{tabular}{|c|c|c|c|c|c|c|}
\hline \multirow[t]{2}{*}{ Variables } & \multirow{2}{*}{$\begin{array}{l}\text { Prevalence } \\
\text { n (\%) }\end{array}$} & \multirow{2}{*}{$\begin{array}{l}\text { Intensity of infection } \\
\text { median (IQR), [min, } \\
\text { max] epg }\end{array}$} & \multicolumn{2}{|c|}{$\begin{array}{l}\text { Generalized Logistic Mixed } \\
\text { Model Multivariate Analysis }\end{array}$} & \multicolumn{2}{|c|}{$\begin{array}{l}\text { Negative binomial regression } \\
\text { Multivariate Analysis †॰ }\end{array}$} \\
\hline & & & $\begin{array}{l}\text { Adjusted Odds } \\
\text { Ratio }(95 \% \mathrm{Cl})\end{array}$ & $\mathrm{p}$-value & $\begin{array}{l}\text { Adjusted } \\
\text { Infection Intensity } \\
\text { Ratio }(95 \% \mathrm{Cl})\end{array}$ & p-value \\
\hline \multicolumn{7}{|l|}{ INDIVIDUAL factors } \\
\hline Age & $\mathrm{n}=6,139$ & $\mathrm{~N}=6,138$ & & $<0.0001$ & & \\
\hline - Adults ( $\geq 15$ years ) & $160 / 3,620(4.4)$ & $0(0-0),[0-12,960]$ & Reference & & Reference & \\
\hline - PreSAC (1-4 years) & $27 / 1,335(2.0)$ & $0(0-0),[0-3,552]$ & $0.21(0.10-0.44)$ & $<0.001$ & $0.10(0.03-0.31)$ & $<0.001$ \\
\hline - SAC (5-14 years) & $12 / 1,184(1.0)$ & $0(0-0),[0-11,100]$ & $0.49(0.29-0.83)$ & 0.008 & $0.29(0.12-0.72)$ & 0.01 \\
\hline Gender & $\mathrm{n}$ total $=6,139$ & $\mathrm{~N}=6,138$ & & 0.004 & & \\
\hline - Male & $113 / 2,828(4.0)$ & $0(0-0),[0-12,960]$ & Reference & & Reference & \\
\hline - Female & $86 / 3,311(2.6)$ & $0(0-0),[0-9,840]$ & $0.56(0.38-0.83)$ & 0.004 & $0.32(0.16-0.64)$ & 0.001 \\
\hline $\begin{array}{l}\text { History of deworming during the } \\
\text { past year }\end{array}$ & $\mathrm{n}$ total $=6,091$ & $\mathrm{~N}=6,090$ & & 0.002 & & \\
\hline - No & $171 / 3,687(4.6)$ & $0(0-0),[0-12,960]$ & Reference & & Reference & \\
\hline - Yes & $28 / 2,404(1.2)$ & $0(0-0),[0-3,048]$ & $0.45(0.27-0.75)$ & $<0.002$ & $0.20(0.08-0.48)$ & $<0.001$ \\
\hline Shoe wearing behavior & $n=6,091$ & $\mathrm{~N}=6,090$ & * & & * & \\
\hline - Shoes & $100 / 3,348(3.0)$ & $0(0-0),[0-12,960]$ & & & & \\
\hline - No shoes & $99 / 2,743(3.6)$ & $0(0-0),[0-11,100]$ & & & & \\
\hline Current school attendance & $\mathrm{n}=6,139$ & 6,138 & * & & * & \\
\hline - No & $152 / 4,294(3.5)$ & $0(0-0),[0-12,960]$ & & & & \\
\hline - Yes & $47 / 1,845(2.5)$ & $0(0-0),[0-11,100]$ & & & & \\
\hline
\end{tabular}

\begin{tabular}{lllll}
\hline HOUSEHOLD factors & & & & \\
$\begin{array}{l}\text { Highest education level in the } \\
\text { household }\end{array}$ & $\mathrm{n}=6,139$ & 6,138 & $*$ & Reference \\
\hline - University/College/Diploma & $4 / 698(0.6)$ & $0(0-0),[0-228]$ & $40.13(2.47-$ & 0.01 \\
\hline - No education & $93 / 1,942(4.8)$ & $0(0-0),[0-12,960]$ & $652.77)$ & $30.92(1.86-$ \\
\hline - Primary & & & $513.88)$ & 0.02 \\
\hline
\end{tabular}




\begin{tabular}{|c|c|c|c|c|c|c|}
\hline \multirow[t]{2}{*}{ Variables } & \multirow{2}{*}{$\begin{array}{l}\text { Prevalence } \\
\text { n (\%) }\end{array}$} & \multirow{2}{*}{$\begin{array}{l}\text { Intensity of infection } \\
\text { median (IQR), [min, } \\
\text { max] epg }\end{array}$} & \multicolumn{2}{|c|}{$\begin{array}{l}\text { Generalized Logistic Mixed } \\
\text { Model Multivariate Analysis } \\
\dagger \S\end{array}$} & \multicolumn{2}{|c|}{$\begin{array}{l}\text { Negative binomial regression } \\
\text { Multivariate Analysis } \neq ผ\end{array}$} \\
\hline & & & $\begin{array}{l}\text { Adjusted Odds } \\
\text { Ratio }(95 \% \mathrm{Cl})\end{array}$ & $p$-value & $\begin{array}{l}\text { Adjusted } \\
\text { Infection Intensity } \\
\text { Ratio }(95 \% \mathrm{Cl})\end{array}$ & p-value \\
\hline - Secondary & $52 / 2,158(2.4)$ & $0(0-0),[0-4,764]$ & & & $\begin{array}{l}19.34(1.21- \\
308.81)\end{array}$ & 0.04 \\
\hline $\begin{array}{l}\text { Quintiles of household asset } \\
\text { index }\end{array}$ & $\mathrm{n}=6,139$ & 6,138 & & $<0.0001$ & * & \\
\hline - 5th quintile (richest) & $16 / 1,558(1.0)$ & $0(0-0),[0-1,440]$ & Reference & & & \\
\hline - 1st quintile (poorest) & $76 / 985(7.7)$ & $0(0-0),[0-12,960]$ & $5.03(2.10-12.01)$ & $<0.001$ & & \\
\hline - 2nd quintile & $51 / 1,043(4.9)$ & $0(0-0),[0-4,764]$ & $3.62(1.51-8.66)$ & 0.001 & & \\
\hline - 3rd quintile & $38 / 1,175(3.2)$ & $0(0-0)[0-9,840]$ & $2.51(1.05-6.00)$ & 0.02 & & \\
\hline - 4th quintile & $18 / 1,378(1.3)$ & $0(0-0),[0-1,104]$ & $0.94(0.36-2.51)$ & 0.91 & & \\
\hline Head of household's occupation & $\mathrm{n}=6,139$ & 6,138 & & 0.03 & & \\
\hline - Others/ Don't know/Refused & $98 / 4,618(2.1)$ & $0(0-0),[0-4,764]$ & Reference & & Reference & \\
\hline - Farmer & $89 / 921(9.7)$ & $0(0-0),[0-12,960]$ & $1.79(1.11-2.90)$ & 0.02 & $3.94(1.67-9.27)$ & 0.002 \\
\hline - Fisher & $12 / 600(2.0)$ & $0(0-0),[0-516]$ & $0.70(0.31-1.60)$ & 0.70 & $0.23(0.05-1.03)$ & 0.06 \\
\hline $\begin{array}{l}\text { Observed floor type : } \\
\text { natural/manmade }\end{array}$ & $\mathrm{n}=6,139$ & 6,138 & * & & & \\
\hline - Man-made floor material & $123 / 5,162(2.4)$ & $0(0-0),[0-11,100]$ & & & Reference & \\
\hline - Natural floor material & $75 / 950(7.9)$ & $0(0-0),[0-12,960]$ & & & $3.02(1.36-6.70)$ & 0.01 \\
\hline - Other/Don't know/Refused & $1 / 27(3.7)$ & $0(0-0),[0-48]$ & & & $\begin{array}{l}3.48(0.02- \\
664.60)\end{array}$ & 0.65 \\
\hline Urbanization & $\mathrm{n}=6,134$ & 6,133 & & 0.02 & & \\
\hline - Urban & $29 / 2,418(1.2)$ & $0(0-0),[0-9,840]$ & Reference & & Reference & \\
\hline - Peri-urban & $146 / 2,922(5.0)$ & $0(0-0),[0-12,960]$ & $2.59(1.25-5.40)$ & 0.01 & $6.18(1.82-20.90)$ & 0.003 \\
\hline - Rural & $24 / 794(3.0)$ & $0(0-0),[0-3,120]$ & $1.37(0.58-3.24)$ & 0.48 & $1.88(0.42-8.46)$ & 0.41 \\
\hline $\begin{array}{l}3 \text { tertiles of population density at } \\
1 \mathrm{~km}^{2}\end{array}$ & $\mathrm{n}=6,134$ & 6,133 & * & & * & \\
\hline $1^{\text {st }}$ tertile $[3 ; 542[$ low & $135 / 2,021(6.7)$ & $0(0-0)[0-12,960]$ & & & & \\
\hline $2^{\text {nd }}$ tertile $[542 ; 1235$ [medium & $43 / 2,072(2.1)$ & $0(0-0),[0-3,624]$ & & & & \\
\hline $3^{\text {rd }}$ tertile [ $\left.1235 ; 2528\right]$ high & $21 / 2,041(1.0)$ & $0(0-0),[0-9,840]$ & & & & \\
\hline
\end{tabular}

\section{WASH factors}

Household water SDG service $\quad n=6,135 \quad 6,134$ 


\begin{tabular}{|c|c|c|c|c|c|c|}
\hline \multirow[t]{2}{*}{ Variables } & \multirow{2}{*}{$\begin{array}{l}\text { Prevalence } \\
\text { n (\%) }\end{array}$} & \multirow{2}{*}{$\begin{array}{l}\text { Intensity of infection } \\
\text { median (IQR), [min, } \\
\text { max] epg }\end{array}$} & \multicolumn{2}{|c|}{$\begin{array}{l}\text { Generalized Logistic Mixed } \\
\text { Model Multivariate Analysis } \\
\text { †§ }\end{array}$} & \multicolumn{2}{|c|}{ 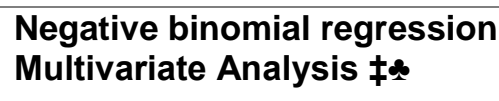 } \\
\hline & & & $\begin{array}{l}\text { Adjusted Odds } \\
\text { Ratio }(95 \% \mathrm{Cl})\end{array}$ & p-value & $\begin{array}{l}\text { Adjusted } \\
\text { Infection Intensity } \\
\text { Ratio }(95 \% \mathrm{Cl})\end{array}$ & p-value \\
\hline - Improved $\leq 30 \mathrm{~min}$ & $141 / 5,098(2.8)$ & $0(0-0),[0-2,124]$ & & & Reference & \\
\hline - Surface water > 30min & $0 / 3(0.0)$ & $0(0-0),[0-3120]$ & & & 0 & - \\
\hline - Surface water $\leq 30 \mathrm{~min}$ & $2 / 16(12.5)$ & $0(0-0),[0-120]$ & & & $\begin{array}{l}45.62(0.76- \\
2726.46)\end{array}$ & 0.07 \\
\hline - Unimproved > 30min & 6/53 (11.3) & $0(0-0),[0-696]$ & & & $\begin{array}{l}13.47(1.62- \\
111.55)\end{array}$ & 0.02 \\
\hline - Unimproved $\leq 30 \mathrm{~min}$ & $39 / 583(6.7)$ & $0(0-0),[0-2,124]$ & & & $1.89(0.69-5.12)$ & 0.21 \\
\hline - Improved > $30 \mathrm{~min}$ & $11 / 382(2.9)$ & $0(0-0),[0-3,120]$ & & & $0.69(0.16-3.01)$ & 0.62 \\
\hline & $\mathrm{n}=5,816$ & & & 0.24 & & \\
\hline $\begin{array}{l}\text { Household sanitation SDG } \\
\text { service }\end{array}$ & $129 / 2,162(6.0)$ & 5,815 & Reference & & & \\
\hline - Open defecation & $3 / 227$ (1.3) & $0(0-0),[0-12,960]$ & $0.50(0.13-1.93)$ & 0.32 & Reference & \\
\hline - Unimproved shared & $1 / 127(0.8)$ & $0(0-0),[0-60]$ & $0.23(0.02-2.24)$ & 0.20 & $0.18(0.01-2.26)$ & 0.19 \\
\hline - Unimproved unshared & $28 / 1,666(1.7)$ & $0(0-0),[0-204]$ & $0.73(0.38-1.37)$ & 0.33 & $0.07(0.002-2.16)$ & 0.13 \\
\hline - Improved shared & $28 / 1,634(1.7)$ & $0(0-0),[50-9,840]$ & $0.48(0.24-0.98)$ & 0.04 & $0.44(0.116-1.25)$ & 0.12 \\
\hline - Improved unshared & $n=5,716$ & $0(0-0),[0-1,440]$ & ** & 0.46 & $0.23(0.07-0.70)$ & 0.01 \\
\hline $\begin{array}{l}\text { Household Hand washing facility } \\
\text { SDG service }\end{array}$ & $64 / 1,881(3.4)$ & 5,715 & Reference & & ** & \\
\hline - No facility & $104 / 3,111(3.3)$ & $0(0-0),[0-12,960]$ & $0.94(0.61-1.44)$ & 0.76 & Reference & \\
\hline - Limited & $13 / 724(1.8)$ & $0(0-0),[0-8,064]$ & $0.61(0.28-1.34)$ & 0.22 & $0.83(0.39-1.77)$ & 0.64 \\
\hline - Basic & & $0(0-0),[0-1,440]$ & & & $0.44(0.11-1.73)$ & 0.24 \\
\hline \multicolumn{7}{|l|}{ ENVIRONMENTAL Factors } \\
\hline Elevation (in meters) & $n=6,134$ & 6,133 & ** & 0.12 & * & \\
\hline $1^{\text {st }}$ tertile $[-1 ; 15[$ (low) & $63 / 2,094(3.0)$ & $0(0-0),[0-12,960]$ & Reference & & & \\
\hline $2^{\text {nd }}$ tertile $[15 ; 30[$ (medium) & $37 / 2,300(1.6)$ & $0(0-0),[0-9,840]$ & $1.07(0.53-2.17)$ & 0.85 & & \\
\hline $3^{\text {rd }}$ tertile $[30 ; 61]$ (high) & $99 / 1,740(5.7)$ & $0(0-0),[0-11,100]$ & $1.73(0.98-3.06)$ & 0.06 & & \\
\hline $\begin{array}{l}\text { Proportion of soil that is sand at } \\
\text { the surface at } 0 \mathrm{~cm}(\%)\end{array}$ & $\mathrm{n}$ total $=6,134$ & 6,133 & * & & * & \\
\hline $1^{\text {st }}$ tertile $[35 ; 55[$ (low) & $37 / 2,143(1.7)$ & $0(0-0),[0-1,176]$ & & & & \\
\hline $2^{\text {nd }}$ tertile $[55 ; 64[$ (medium) & $40 / 2,001(2.0)$ & $0(0-0),[0-3,624]$ & & & & \\
\hline
\end{tabular}




\begin{tabular}{|c|c|c|c|c|c|c|}
\hline \multirow[t]{2}{*}{ Variables } & \multirow{2}{*}{$\begin{array}{l}\text { Prevalence } \\
\text { n (\%) }\end{array}$} & \multirow{2}{*}{$\begin{array}{l}\text { Intensity of infection } \\
\text { median (IQR), [min, } \\
\text { max] epg }\end{array}$} & \multicolumn{2}{|c|}{$\begin{array}{l}\text { Generalized Logistic Mixed } \\
\text { Model Multivariate Analysis } \\
\dagger \S\end{array}$} & \multicolumn{2}{|c|}{ 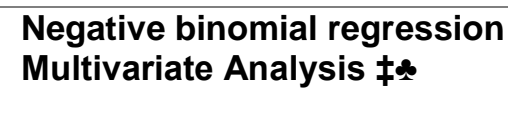 } \\
\hline & & & $\begin{array}{l}\text { Adjusted Odds } \\
\text { Ratio }(95 \% \mathrm{Cl})\end{array}$ & p-value & $\begin{array}{l}\text { Adjusted } \\
\text { Infection Intensity } \\
\text { Ratio }(95 \% \mathrm{Cl})\end{array}$ & p-value \\
\hline $3^{\text {rd }}$ tertile $[64 ; 78]$ (high) & $122 / 1,990(6.1)$ & $0(0-0),[0-12,960]$ & & & & \\
\hline $\begin{array}{l}\text { Soil acidity }(\mathrm{pH} \mathrm{KCL}) \text { at everage } \\
\text { depth }(0-5-15 \mathrm{~cm})\end{array}$ & $\mathrm{n}$ total $=6,134$ & 6,133 & * & & * & \\
\hline $1^{\text {st }}$ tertile $[4.8 ; 5.1[$ (low) & $40 / 2,810(2.0)$ & $0(0-0),[0-11,100]$ & & & & \\
\hline $2^{\text {nd }}$ tertile $[5.1 ; 5.2[$ (medium) & $90 / 1,230(4.0)$ & $0(0-0),[0-9,840]$ & & & & \\
\hline $3^{\text {rd }}$ tertile $[5.2 ; 5.7]$ (high) & 69/2,094 (3.7) & $0(0-0),[0-12,960]$ & & & & \\
\hline $\begin{array}{l}\text { MODIS daytime land surface } \\
\text { temperature mean for } 2018 \\
\text { ( }{ }^{\circ} \text { celsius) }\end{array}$ & $\mathrm{n}=6,134$ & 6,133 & * & & * & \\
\hline $1^{\text {st }}$ tertile $[26.2 ; 29.6[$ (low) & $71 / 2,097(3.4)$ & $0(0-0),[0-11,100]$ & & & & \\
\hline $2^{\text {nd }}$ tertile $[29.6 ; 31.9[$ (medium) & $109 / 2,407(4.5)$ & $0(0-0),[0-12,960]$ & & & & \\
\hline $3^{\text {rd }}$ tertile $[31.9 ; 32.8]$ (high) & $19 / 1,630(1.2)$ & $0(0-0),[0-3,624]$ & & & & \\
\hline $\begin{array}{l}\text { MODIS Enhanced Vegetation } \\
\text { Index (EVI) mean for } 2018\end{array}$ & $\mathrm{n}=6,134$ & 6,133 & * & & * & \\
\hline $1^{\text {st }}$ tertile $[0.04 ; 0.2[$ (low) & $26 / 2,086(1.2)$ & $(0-0),[0-9,840]$ & & & & \\
\hline $2^{\text {nd }}$ tertile $[0.2 ; 0.3[$ (medium) & $35 / 2,061(1.7)$ & $(0-0),[0-3,624]$ & & & & \\
\hline $3^{\text {rd }}$ tertile $[0.3 ; 0.4]$ (high) & $138 / 1,987(6.9)$ & $(0-0),[0-12,960]$ & & & & \\
\hline $\begin{array}{l}\text { MODIS normalized difference } \\
\text { vegetation index (NDVI) mean } \\
\text { for } 2018\end{array}$ & $\mathrm{n}=6,134$ & 6,133 & ** & 0.007 & ** & \\
\hline $1^{\text {st }}$ tertile $[0.06 ; 0.3[$ (low) & $27 / 2,063(1.3)$ & $(0-0),[0-9,840]$ & Reference & & Reference & \\
\hline $2^{\text {nd }}$ tertile $[0.3 ; 0.4[$ (medium) & $33 / 2,079(1.6)$ & $(0-0),[0-3,624]$ & $0.72(0.33-1.56)$ & 0.41 & $0.44(0.12-1.61)$ & 0.21 \\
\hline $3^{\text {rd }}$ tertile $[0.4 ; 0.6]$ (high) & $139 / 1,992(7.0)$ & $(0-0),[0-12,960]$ & $2.00(0.93-4.28)$ & 0.07 & $3.31(0.85-12.93)$ & 0.08 \\
\hline Aridity index & $\mathrm{n}$ total $=6,134$ & 6,133 & * & & * & \\
\hline $1^{\text {st }}$ tertile $[0.59 ; 0.61[$ (low) & $81 / 2,083(3.9)$ & $(0-0),[0-9,840]$ & & & & \\
\hline $2^{\text {nd }}$ tertile $[0.61 ; 0.62[$ (medium) & $50 / 2,099(2.4)$ & $(0-0),[0-8,064]$ & & & & \\
\hline $3^{\text {rd }}$ tertile $[0.62 ; 0.65]$ (high) & $68 / 1,952(3.5)$ & $(0-0),[0-12,960]$ & & & & \\
\hline
\end{tabular}

† Adjusted Generalized logistic mixed model estimating equations with exchangeable correlation structure.

$\S 5,366$ observations included in fully adjusted model.

$\ddagger$ Adjusted zero-inflated negative binomial regression model, inflating for sex and age (1-4 years, 5-14 years, 15 years), with an exchangeable correlation matrix. 


\begin{tabular}{|c|c|c|c|c|c|c|}
\hline \multirow[t]{2}{*}{ Variables } & \multirow{2}{*}{$\begin{array}{l}\text { Prevalence } \\
\text { n (\%) }\end{array}$} & \multirow{2}{*}{$\begin{array}{l}\text { Intensity of infection } \\
\text { median (IQR), [min, } \\
\text { max] epg }\end{array}$} & \multicolumn{2}{|c|}{$\begin{array}{l}\text { Generalized Logistic Mixed } \\
\text { Model Multivariate Analysis } \\
\dagger \S\end{array}$} & \multicolumn{2}{|c|}{$\begin{array}{l}\text { Negative binomial regression } \\
\text { Multivariate Analysis } \ddagger^{\circ}\end{array}$} \\
\hline & & & $\begin{array}{l}\text { Adjusted Odds } \\
\text { Ratio }(95 \% \mathrm{Cl})\end{array}$ & p-value & $\begin{array}{l}\text { Adjusted } \\
\text { Infection Intensity } \\
\text { Ratio }(95 \% \mathrm{Cl})\end{array}$ & p-value \\
\hline
\end{tabular}

\& 5,364 observations included in fully adjusted model.

* Variable dropped from fully adjusted model during model adjustment process using lowest AIC criteria.

** Variable in the final adjusted model but with no significant category

Abbreviation: School Aged Children (SAC), Pre School Aged Children (PSAC), confidence interval (CI), interquartile range (IQR), Moderate Resolution Imaging Spectroradiometer (MODIS) 
Table 4 : Factors associated with Ascaris infection prevalence in Comé, Bénin: findings from a baseline prevalence survey using Kato-Katz technique

\begin{tabular}{|c|c|c|c|c|c|}
\hline Variables & 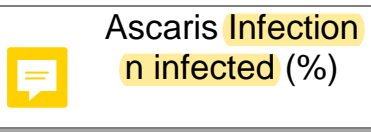 & $\begin{array}{l}\text { Univariate Analysis } \\
\text { Odds Ratio }(95 \% \mathrm{Cl})\end{array}$ & $p$-value & $\begin{array}{l}\text { Multivariate Analysis } \\
\text { Adjusted Odds Ratio } \\
(95 \% \mathrm{Cl})\end{array}$ & $\mathrm{p}$-value \\
\hline \multicolumn{6}{|l|}{ INDIVIDUAL factors } \\
\hline Age & $n=6,139$ & & 0.02 & & \\
\hline - Adults ( $\geq 15$ years ) & $62 / 3,620(1.71)$ & Reference & & Ref & \\
\hline - PreSAC (1-4 years) & $24 / 1,335(2.03)$ & $1.3(0.7-2.2)$ & 0.42 & $1.6(0.8-3.1)$ & 0.14 \\
\hline - SAC (5-14 years) & $40 / 1,184(3.00)$ & $2.0(1.2-3.3)$ & 0.005 & $2.0(1.1-3.6)$ & 0.01 \\
\hline Gender & $n=6,139$ & & & & \\
\hline - Male & $74 / 2,828(2.62)$ & Reference & & & \\
\hline - Female & $52 / 3,311(1.57)$ & $0.5(0.3-0.8)$ & 0.003 & $0.5(0.3-0.9)$ & 0.02 \\
\hline $\begin{array}{l}\text { History of deworming during the past } \\
\text { year }\end{array}$ & $\mathrm{n}=6,091$ & & & * & \\
\hline - No & $98 / 3,687(2.66)$ & Reference & & & \\
\hline - Yes & $28 / 2,404(1.16)$ & $0.7(0.4-1.2)$ & 0.24 & & \\
\hline Shoe wearing behavior & $\mathrm{n}=6,091$ & & & * & \\
\hline - Shoes & $53 / 3,348(1.58)$ & Reference & & & \\
\hline - No shoes & $73 / 2,743(2.66)$ & $0.8(0.5-1.3)$ & 0.41 & & \\
\hline Current school attendance & $\mathrm{n}=6,139$ & & & ** & \\
\hline - No & $72 / 4,294(1.68)$ & Reference & & & \\
\hline - Yes & $54 / 1,845(2.93)$ & $2.0(1.3-3.0)$ & 0.001 & & \\
\hline \multicolumn{6}{|l|}{ HOUSEHOLD factors } \\
\hline $\begin{array}{l}\text { Highest education level in the } \\
\text { household }\end{array}$ & $\mathrm{n}=6,139$ & & 0.08 & $\star *$ & \\
\hline - University/College/Diploma & $3 / 698(0.43)$ & Reference & & & \\
\hline - No education & $41 / 1,942(2.11)$ & $2.4(0.6-9.0)$ & 0.21 & & \\
\hline - Primary & $45 / 1,341(3.36)$ & $4.2(1.1-16.6)$ & 0.04 & & \\
\hline - Secondary & $37 / 2,158(1.71)$ & $3.1(0.8-11.9)$ & 0.10 & & \\
\hline Quintiles of household asset index & $\mathrm{n}=6,139$ & & 0.14 & ** & \\
\hline - 5th quintile (richest) & $13 / 1,558(0.83)$ & Reference & & & \\
\hline - 1st quintile (poorest) & $43 / 985$ & $1.8(0.8-4.1)$ & 0.15 & & \\
\hline - 2nd quintile & $30 / 1,043(2.88)$ & $1.7(0.7-3.9)$ & 0.21 & & \\
\hline - 3rd quintile & $22 / 1,175(1.87)$ & $0.9(0.4-2.0)$ & 0.72 & & \\
\hline
\end{tabular}




\begin{tabular}{|c|c|c|c|c|c|}
\hline Variables & $\begin{array}{l}\text { Ascaris Infection } \\
\text { n infected (\%) }\end{array}$ & $\begin{array}{l}\text { Univariate Analysis } \\
\text { Odds Ratio }(95 \% \mathrm{Cl})\end{array}$ & $p$-value & $\begin{array}{l}\text { Multivariate Analysis } \\
\text { Adjusted Odds Ratio } \\
(95 \% \mathrm{Cl})\end{array}$ & $p$-value \\
\hline - 4th quintile & 18/1,378 (1.31) & $0.9(0.4-2.3)$ & 0.94 & & \\
\hline Head of household's occupation & $\mathrm{n}=6,139$ & & 0.21 & * & \\
\hline - Others/ Don't know/Refused & $62 / 4,618(1.34)$ & Reference & & & \\
\hline - Farmer & $13 / 921(1.41)$ & $0.9(0.4-1.9)$ & 0.86 & & \\
\hline - Fisher & $51 / 600(8.50)$ & $1.6(0.9-2.6)$ & 0.10 & & \\
\hline Observed floor type : natural/manmade & $\mathrm{n}=6,139$ & & 0.99 & * & \\
\hline - Man-made floor material & $97 / 5,162(1.88)$ & Reference & & & \\
\hline - Natural floor material & $29 / 950(3.05)$ & $1.0(0.6-1.7)$ & 0.99 & & \\
\hline - Other/Don't know/Refused & $1 / 27(3.7)$ & - & - & & \\
\hline Urbanization & $\mathrm{n}=6,134$ & & 0.26 & * & \\
\hline - Urban & $69 / 2,418(2.85)$ & Reference & & & \\
\hline - Peri-urban & $14 / 2,922(0.48)$ & $0.4(0.1-1.2)$ & 0.11 & & \\
\hline - Rural & $43 / 794(5.42)$ & $0.8(0.5-1.4)$ & 0.51 & & \\
\hline 3 tertiles of population density at $1 \mathrm{~km}$ & $\mathrm{n}=6,134$ & & 0.005 & * & \\
\hline - $1^{\text {st }}$ tertile $[3 ; 542[$ (low) & $19 / 2,021(0.94)$ & Reference & & & \\
\hline - $2^{\text {nd }}$ tertile $[542 ; 1235[$ (medium) & $57 / 2,072(2.75)$ & $1.6(0.8-3.0)$ & 0.14 & & \\
\hline - $3^{\text {rd }}$ tertile [ $\left.1235 ; 2528\right]$ (high) & $50 / 2,041(2.45)$ & $2.9(1.5-5.9)$ & 0.002 & & \\
\hline \multicolumn{6}{|l|}{ WASH factors } \\
\hline Household water SDG service modified & $\mathrm{n}=6,063$ & & 0.97 & * & \\
\hline - Improved $\leq 30 \mathrm{~min}$ & $107 / 5,098(2.10)$ & Reference & & & \\
\hline - Surface water $>30 \mathrm{~min}$ & $0 / 3(0.0)$ & 1 & & & \\
\hline - Surface water $\leq 30 \mathrm{~min}$ & $0 / 16(0.0)$ & 1 & & & \\
\hline - Unimproved > 30min & $0 / 53(0.0)$ & 1 & & & \\
\hline - Unimproved $\leq 30 \mathrm{~min}$ & $8 / 583(1.37)$ & $1.1(0.4-2.7)$ & 0.85 & & \\
\hline - Improved > $30 \mathrm{~min}$ & $11 / 382(2.88)$ & $1.1(0.5-2.4)$ & 0.84 & & \\
\hline \multicolumn{6}{|l|}{-} \\
\hline Household sanitation SDG service & $n=5,816$ & & 0.65 & $\star \star$ & \\
\hline - Open defecation & $84 / 2,162(3.89)$ & Reference & & Ref & \\
\hline - Unimproved shared & $5 / 227(2.20)$ & $1.3(0.4-4.3)$ & 0.65 & $1.6(0.4-6.8)$ & 0.51 \\
\hline - Unimproved unshared & $2 / 127(1.57)$ & $1.2(0.2-6.9)$ & 0.84 & $1.1(0.1-11.5)$ & 0.94 \\
\hline - Improved shared & $23 / 1,666(1.38)$ & $0.9(0.5-1.7)$ & 0.74 & $1.1(0.5-2.1)$ & 0.87 \\
\hline - Improved unshared & $11 / 1,634(0.67)$ & $0.6(0.3-1.2)$ & 0.16 & $0.8(0.3-1.8)$ & 0.55 \\
\hline
\end{tabular}




\begin{tabular}{|c|c|c|c|c|c|}
\hline Variables & $\begin{array}{l}\text { Ascaris Infection } \\
\mathrm{n} \text { infected }(\%)\end{array}$ & $\begin{array}{l}\text { Univariate Analysis } \\
\text { Odds Ratio }(95 \% \mathrm{Cl})\end{array}$ & $\mathrm{p}$-value & $\begin{array}{l}\text { Multivariate Analysis } \\
\text { Adjusted Odds Ratio } \\
(95 \% \mathrm{Cl})\end{array}$ & $p$-value \\
\hline $\begin{array}{l}\text { Household Hand washing facility SDG } \\
\text { service }\end{array}$ & $n=5,716$ & & 0.09 & $* *$ & \\
\hline - No facility & $13 / 1,881(1.80)$ & Reference & & Ref & \\
\hline - Limited & $16 / 3,111(0.85)$ & $2.6(1.2-5.6)$ & 0.01 & $1.8(0.8-3.6)$ & 0.13 \\
\hline - Basic & $71 / 724(2.28)$ & $1.9(0.7-4.8)$ & 0.20 & $1.3(0.5-3.4)$ & 0.54 \\
\hline \multicolumn{6}{|l|}{ ENVIRONMENTAL Factors } \\
\hline Elevation (in meters) & $\mathrm{n}=6,134$ & & 0.02 & * & \\
\hline $1^{\text {st }}$ tertile $[-1 ; 15[$ low) & $88 / 2,094(4.20)$ & Reference & & & \\
\hline $2^{\text {nd }}$ tertile $[15 ; 30[$ (medium) & $25 / 2,300(1.09)$ & $0.6(0.3-1.2)$ & 0.17 & & \\
\hline $3^{\text {rd }}$ tertile $[30 ; 61]$ (high) & $13 / 1,740(0.75)$ & $0.3(0.1-0.7)$ & 0.01 & & \\
\hline $\begin{array}{l}\text { Proportion of soil that is sand at the } \\
\text { surface at } 0 \mathrm{~cm}(\%)\end{array}$ & $n=6,134$ & & 0.09 & * & \\
\hline $1^{\text {st }}$ tertile $[35 ; 55[$ (low) & $101 / 2,143(4.71)$ & Reference & & & \\
\hline $2^{\text {nd }}$ tertile $[55 ; 64[$ (medium) & $9 / 2,001(0.45)$ & $0.5(0.2-1.1)$ & 0.10 & & \\
\hline $3^{\text {rd }}$ tertile $[64 ; 78]$ (high) & $16 / 1,990(0.80)$ & $0.5(0.2-1.1)$ & 0.07 & & \\
\hline $\begin{array}{l}\text { Soil acidity }(\mathrm{pH} \mathrm{KCL}) \text { at average depth } \\
(0-5-15 \mathrm{~cm})\end{array}$ & $n=6,134$ & & 0.001 & & \\
\hline $1^{\text {st }}$ tertile $[4.8 ; 5.1[$ (low) & $14 / 2,810(0.69)$ & Reference & & Ref & \\
\hline $2^{\text {nd }}$ tertile $[5.1 ; 5.2[$ (medium) & $29 / 1,230(1.31)$ & $2.2(1.0-5.0)$ & 0.06 & $2.0(0.9-4.2)$ & 0.20 \\
\hline $3^{\text {rd }}$ tertile $[5.2 ; 5.7]$ (high) & $83 / 2,094(4.42)$ & $4.1(1.9-8.8)$ & 0.001 & $4.8(1.8-13.1)$ & 0.002 \\
\hline $\begin{array}{l}\text { MODIS daytime land surface } \\
\text { temperature mean for } 2018 \text { ( }{ }^{\circ} \text { celsius) }\end{array}$ & $n=6,134$ & & 0.001 & & \\
\hline $1^{\text {st }}$ tertile $[26.2 ; 29.6[$ (low) & $115 / 2,097(5.48)$ & Reference & & & \\
\hline $2^{\text {nd }}$ tertile $[29.6 ; 31.9[$ (medium) & $7 / 2,407(0.29)$ & $0.1(0.03-0.4)$ & 0.001 & $\begin{array}{l}0.12 \\
(0.03-0.44)\end{array}$ & 0.001 \\
\hline $3^{\text {rd }}$ tertile $[31.9 ; 32.8]$ (high) & $4 / 1,630(0.25)$ & $0.1(0.02-0.5)$ & 0.005 & $\begin{array}{l}0.17 \\
(0.03-0.91)\end{array}$ & 0.038 \\
\hline $\begin{array}{l}\text { MODIS Enhanced Vegetation Index } \\
\text { (EVI) mean for } 2018\end{array}$ & $\mathrm{n}=6,134$ & & 0.36 & * & \\
\hline $1^{\text {st }}$ tertile $[0.04 ; 0.2[$ (low) & $20 / 2,086(0.96)$ & Reference & & & \\
\hline $2^{\text {nd }}$ tertile $[0.2 ; 0.3[$ (medium) & $67 / 2,061(3.25)$ & $1.1(0.5-2.4)$ & 0.72 & & \\
\hline $3^{\text {rd }}$ tertile $[0.3 ; 0.4]$ (high) & $39 / 1,987(1.96)$ & $0.8(0.3-1.8)$ & 0.54 & & \\
\hline
\end{tabular}




\begin{tabular}{|c|c|c|c|c|c|}
\hline Variables & $\begin{array}{c}\text { Ascaris Infection } \\
\text { n infected (\%) }\end{array}$ & $\begin{array}{l}\text { Univariate Analysis } \\
\text { Odds Ratio }(95 \% \mathrm{Cl})\end{array}$ & $p$-value & $\begin{array}{l}\text { Multivariate Analysis } \\
\text { Adjusted Odds Ratio } \\
(95 \% \mathrm{Cl})\end{array}$ & $\mathrm{p}$-value \\
\hline $\begin{array}{l}\text { MODIS normalized difference } \\
\text { vegetation index (NDVI) mean for } \\
2018\end{array}$ & $n=6,134$ & & 0.90 & * & \\
\hline $1^{\text {st }}$ tertile $[0.06 ; 0.3[$ (low) & 22/2,063 (1.07) & Reference & & & \\
\hline $2^{\text {nd }}$ tertile $[0.3 ; 0.4[$ (medium) & $65 / 2,079(3.13)$ & $1.1(0.5-2.1)$ & 0.86 & & \\
\hline $3^{\text {rd }}$ tertile $[0.4 ; 0.6]$ (high) & $39 / 1,992(1.96)$ & $0.9(0.4-2.0)$ & 0.87 & & \\
\hline Aridity index & $n=6,134$ & & 0.54 & * & \\
\hline $1^{\text {st }}$ tertile $[0.59 ; 0.61[$ (low) & $15 / 2,083(0.72)$ & Reference & & & \\
\hline $2^{\text {nd }}$ tertile $[0.61 ; 0.62[$ (medium) & $92 / 2,099(4.38)$ & $0.6(0.2-1.6)$ & 0.33 & & \\
\hline $3^{\text {rd }}$ tertile $[0.65 ; 0.65]$ (high) & $19 / 1,962(0.97)$ & $1.0(0.3-3.3)$ & 0.96 & & \\
\hline
\end{tabular}

* Variable dropped from fully adjusted model during model adjustment process using lowest AIC criteria.

** Variable in the final adjusted model but with no significant category

Abbreviation: School Aged Children (SAC), Pre School Aged Children (PSAC), confidence interval (CI), interquartile range (IQR), Moderate Resolution Imaging Spectroradiometer (MODIS) 



\section{SUPPLEMENTARY DATA}

Table S1: Burden of moderate to high intensity (MHI) STH infection in the study population by age group, during DeWorm3 baseline analysis in Comé, Bénin

\begin{tabular}{llllll}
\hline Age group & $\begin{array}{c}\mathrm{N} \\
=6,139\end{array}$ & MHI STH & $\begin{array}{l}\text { MHI } \\
\text { Hookworm }\end{array}$ & MHI Ascaris & $\begin{array}{l}\text { MHI } \\
\text { Trichuris }\end{array}$ \\
\hline - Adults $(\geq 15 \mathrm{y})$ & 3,620 & $24(0.7 \%)$ & $7(0.2)$ & $17(0.5 \%)$ & 0 \\
\hline - PSAC $(1-4 \mathrm{y})$ & 1,335 & $14(1.1 \%)$ & $1(0.1 \%)$ & $13(1.0 \%)$ & 0 \\
\hline - SAC $(5-14 \mathrm{y})$ & 1,184 & $28(2.3 \%)$ & $2(0.2 \%)$ & $25(2.1 \%)$ & $1(0.0)$ \\
\hline
\end{tabular}




\section{SUPPLEMENTARY DATA}

Table S2: Burden of moderate to high STH infection in infected individuals by age group and yender, during DeWorm3 baseline analysis in Comé, Bénin

\begin{tabular}{|l|l|l|l|l|l|}
\hline & N=66 & Hookworm & Ascaris & Trichuris & Total $(\%)$ \\
\hline \multirow{2}{*}{ PSAC } & Male & 1 & 5 & - & $6(9)$ \\
\cline { 2 - 6 } & Female & - & 8 & - & $8(12.1)$ \\
\hline \multirow{3}{*}{ SAC } & Male & 2 & 20 & 1 & $23(34.8)$ \\
\cline { 2 - 6 } & Female & - & 5 & - & $5(7.5)$ \\
\hline \multirow{2}{*}{ Adults } & Male & 4 & 12 & - & $16(24.2)$ \\
\cline { 2 - 6 } & Female & 3 & 5 & - & $8(12.1)$ \\
\hline Total & & $10(15.1)$ & $55(83.3)$ & $1(1.5)$ & $66(100)$ \\
\hline
\end{tabular}




\section{SUPPLEMENTARY DATA}

Table S3: Factors univariately associated with hookworm infection in Comé, Bénin: findings from DeWorm3 cluster randomized trial baseline pretreatment survey using generalized logistic mixed model.

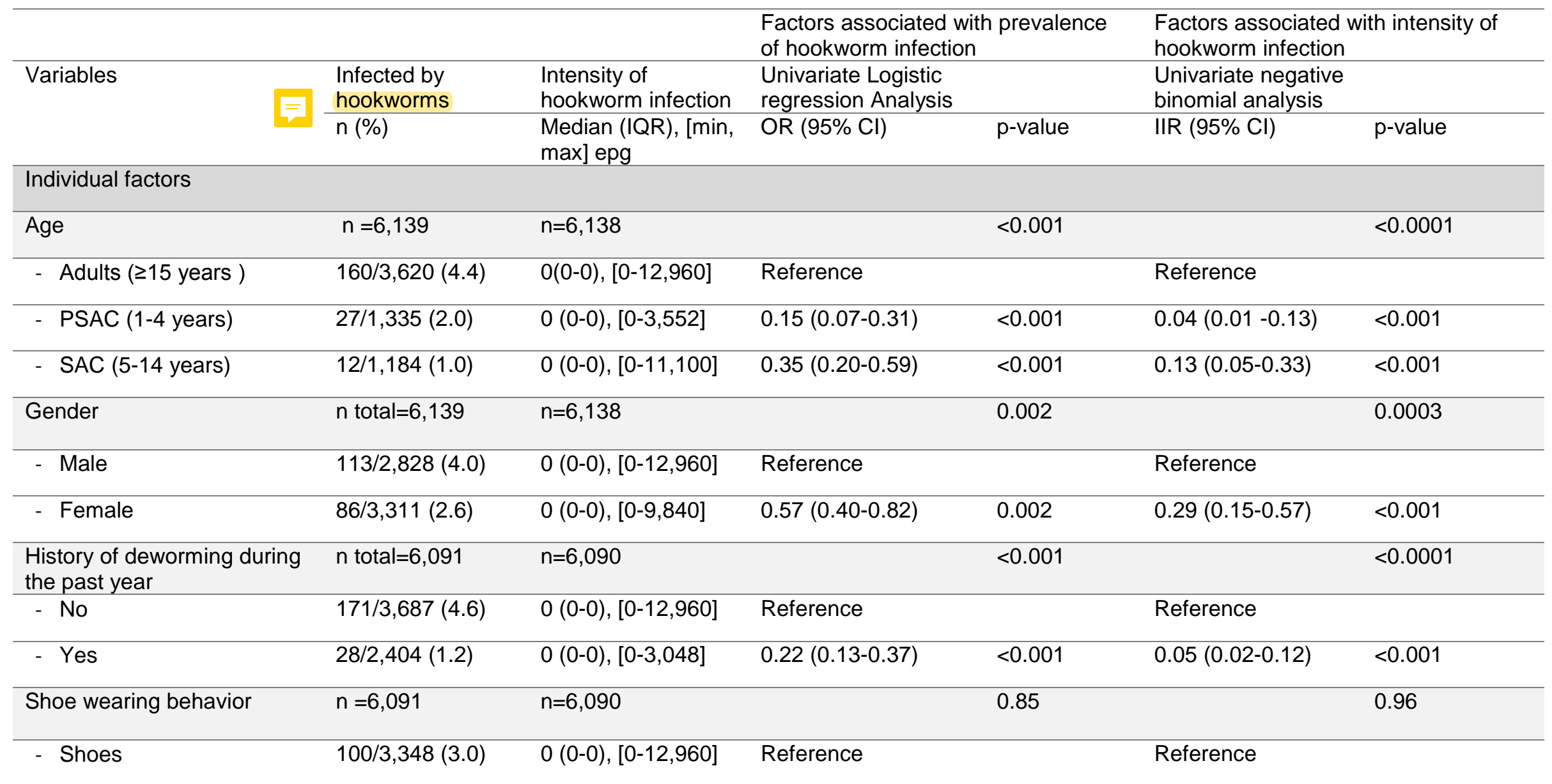




\begin{tabular}{|c|c|c|c|c|c|c|}
\hline - No shoes & $99 / 2,743(3.6)$ & $0(0-0),[0-11,100]$ & $1.03(0.72-1.48)$ & 0.85 & $0.98(0.50-1.94)$ & 0.96 \\
\hline Current school attendance & $\mathrm{n}=6,139$ & $n=6,138$ & & 0.29 & & 0.18 \\
\hline - No & $152 / 4,294(3.5)$ & $0(0-0),[0-12,960]$ & Reference & & Reference & \\
\hline - Yes & $47 / 1,845(2.5)$ & $0(0-0),[0-11,100]$ & $0.80(0.53-1.21)$ & 0.29 & $0.60(0.28-1.26)$ & 0.18 \\
\hline \multicolumn{7}{|l|}{ Household factors } \\
\hline $\begin{array}{l}\text { Highest education level in } \\
\text { the household }\end{array}$ & $\mathrm{n}=6,139$ & $n=6,138$ & & 0.002 & & 0.0015 \\
\hline $\begin{array}{l}\text { - University/College/Diplo } \\
\text { ma }\end{array}$ & 4/698 (0.6) & $0(0-0),[0-228]$ & Reference & & Reference & \\
\hline - No education & $93 / 1,942(4.8)$ & $0(0-0),[0-12,960]$ & $6.8(2.21-20.86)$ & 0.001 & $39.68(5.64-279.16)$ & $<0.001$ \\
\hline - Primary & $50 / 1,341(3.7)$ & $0(0-0),[0-11,100]$ & $5.0(1.60-15.60)$ & 0.006 & $26.57(3.68-191.56)$ & 0.001 \\
\hline - Secondary & $52 / 2,158(2.4)$ & $0(0-0),[0-4,764]$ & $3.66(1.20-11.18)$ & 0.023 & $15.87(2.31-108.97)$ & 0.005 \\
\hline $\begin{array}{l}\text { Quintiles of household asset } \\
\text { index }\end{array}$ & $n=6,139$ & $n=6,138$ & & $<0.001$ & & $<0.0001$ \\
\hline - 5th quintile (high) & 16/1,558 (1.0) & $0(0-0),[0-1,440]$ & Reference & & Reference & \\
\hline - 1st quintile (low) & 76/985 (7.7) & $0(0-0),[0-12,960]$ & $7.14(3.45-14.78)$ & $<0.001$ & $\begin{array}{l}53.53(15.18- \\
188.83)\end{array}$ & $<0.001$ \\
\hline - 2nd quintile & $51 / 1,043(4.9)$ & $0(0-0),[0-4,764]$ & $4.85(2.38-9.90)$ & $<0.001$ & $22.03(6.35-76.43)$ & $<0.001$ \\
\hline - 3rd quintile & $38 / 1,175(3.2)$ & $0(0-0)[0-9,840]$ & $2.84(1.41-5.70)$ & 0.003 & $7.10(2.09-24.07)$ & 0.002 \\
\hline - 4th quintile & 18/1,378 (1.3) & $0(0-0),[0-1,104]$ & $1.19(0.55-2.54)$ & 0.66 & $1.32(0.36-4.80)$ & 0.67 \\
\hline $\begin{array}{l}\text { Head of household's } \\
\text { occupation }\end{array}$ & $\mathrm{n}=6,139$ & $n=6,138$ & & $<0.0001$ & & $<0.0001$ \\
\hline $\begin{array}{l}\text { - Others/ Don't } \\
\text { know/Refused }\end{array}$ & $98 / 4,618(2.1)$ & $0(0-0),[0-4,764]$ & Reference & & Reference & \\
\hline
\end{tabular}




\begin{tabular}{|c|c|c|c|c|c|c|}
\hline - Farmer & $89 / 921(9.7)$ & $0(0-0),[0-12,960]$ & $3.64(2.21-5.97)$ & $<0.001$ & $18.10(7.39-44.32)$ & $<0.001$ \\
\hline - Fisher & $12 / 600(2.0)$ & $0(0-0),[0-516]$ & $1.17(0.54-2.54)$ & 0.69 & $0.72(0.17-3.14)$ & 0.67 \\
\hline $\begin{array}{l}\text { Observed floor type : } \\
\text { natural/manmade }\end{array}$ & $n=6,139$ & $n=6,138$ & & $<0.0001$ & & $<0.0001$ \\
\hline - Man-made floor material & $123 / 5,162(2.4)$ & $0(0-0),[0-11,100]$ & Reference & & Reference & \\
\hline - Natural floor material & 75/950 (7.9) & $0(0-0),[0-12,960]$ & $2.90(1.86-4.53)$ & $<0.001$ & $11.49(5.13-25.72)$ & $<0.001$ \\
\hline $\begin{array}{l}\text { - Other/Don't } \\
\text { know/Refused }\end{array}$ & $1 / 27(3.7)$ & $0(0-0),[0-48]$ & $2.94(0.24-35.64)$ & 0.40 & $4.92(0.02-1068.60)$ & 0.562 \\
\hline Urbanization & $\mathrm{n}=6,134$ & $\mathrm{n}=6,133$ & & $<0.0001$ & & $<0.0001$ \\
\hline - Urban & $29 / 2,418(1.2)$ & $0(0-0),[0-9,840]$ & Reference & & Reference & \\
\hline - Peri-urban & $146 / 2,922(5.0)$ & $0(0-0),[0-12,960]$ & $4.34(2.30-8.20)$ & $<0.0001$ & $22.47(7.15-70.65)$ & $<0.001$ \\
\hline - Rural & $24 / 794(3.0)$ & $0(0-0),[0-3,120]$ & $2.67(1.09-6.57)$ & 0.03 & $6.35(1.23-32.75)$ & 0.03 \\
\hline Population density at $1 \mathrm{~km}$ & $n=6,134$ & $n=6,133$ & & $<0.0001$ & & $<0.0001$ \\
\hline $1^{\text {st }}$ tertile $[3 ; 542[$ & $135 / 2,021(6.7)$ & $0(0-0)[0-12,960]$ & Reference & & Reference & \\
\hline $2^{\text {nd }}$ tertile $[542 ; 1235[$ & $43 / 2,072(2.1)$ & $0(0-0),[0-3,624]$ & $0.39(0.23-0.69)$ & 0.001 & $0.15(0.05-0.42)$ & $<0.001$ \\
\hline $3^{\text {rd }}$ tertile $[1235 ; 2528]$ & $21 / 2,041(1.0)$ & $0(0-0),[0-9,840]$ & $0.15(0.73-0.32)$ & $<0.001$ & $0.02(0.005-0.07)$ & $<0.001$ \\
\hline \multicolumn{7}{|l|}{ WASH factors } \\
\hline Household water service & $\mathrm{n}=6,135$ & $n=6,134$ & & 0.001 & & - \\
\hline - Improved $\leq 30 \mathrm{~min}$ & $141 / 5,098(2.8)$ & $0(0-0),[0-2,124]$ & Reference & & Reference & \\
\hline - Surface water > 30min & $0 / 3(0.0)$ & $0(0-0),[0-3120]$ & 0 & - & 0 & - \\
\hline - Surface water $\leq 30 \mathrm{~min}$ & 2/16 (12.5) & $0(0-0),[0-120]$ & $11.14(1.20-103.68)$ & 0.034 & $\begin{array}{l}75.75(1.31- \\
4390.32\end{array}$ & 0.04 \\
\hline
\end{tabular}




\begin{tabular}{|c|c|c|c|c|c|c|}
\hline - Unimproved > 30min & 6/53 (11.3) & $0(0-0),[0-696]$ & $5.77(1.58-21.08)$ & 0.008 & $\begin{array}{l}97.66(8.79- \\
1085.16)\end{array}$ & $<0.001$ \\
\hline - Unimproved $\leq 30 \mathrm{~min}$ & $39 / 583(6.7)$ & $0(0-0),[0-2,124]$ & $2.72(1.54-4.81)$ & 0.001 & $10.70(3.91-29.27)$ & $<0.001$ \\
\hline - Improved > $30 \mathrm{~min}$ & $11 / 382(2.9)$ & $0(0-0),[0-3,120]$ & $0.96(0.43-2.13)$ & 0.914 & $0.95(0.22-4.09)$ & 0.95 \\
\hline Household sanitation service & $n=5,816$ & $n=5,815$ & & 0.0001 & & $<0.0001$ \\
\hline - Open defecation & $129 / 2,162(6.0)$ & $0(0-0),[0-12,960]$ & Reference & 0.044 & Reference & \\
\hline - Unimproved shared & $3 / 227(1.3)$ & $0(0-0),[0-60]$ & $0.24(0.06-0.96)$ & 0.064 & $0.03(0.002-0.39)$ & 0.01 \\
\hline - Unimproved unshared & $1 / 127(0.8)$ & $0(0-0),[0-204]$ & $0.12(0.01-1.13)$ & $<0.001$ & $0.02(0.0006-0.54)$ & 0.02 \\
\hline - Improved shared & 28/1,666 (1.7) & $0(0-0),[50-9,840]$ & $0.29(0.16-0.54)$ & $<0.001$ & $0.08(0.03-0.23)$ & $<0.001$ \\
\hline - Improved unshared & $28 / 1,634(1.7)$ & $0(0-0),[0-1,440]$ & $0.28(0.15-0.52)$ & 0.1705 & $0.07(0.02-0.20)$ & $<0.001$ \\
\hline $\begin{array}{l}\text { Household hand washing } \\
\text { facility service }\end{array}$ & $n=5,716$ & $\mathrm{n}=5,715$ & & & & 0.007 \\
\hline - No facility & $64 / 1,881(3.4)$ & $0(0-0),[0-12,960]$ & Reference & & Reference & \\
\hline - Limited & $104 / 3,111(3.3)$ & $0(0-0),[0-8,064]$ & $1.18(0.76-1.83)$ & 0.452 & $1.30(0.59-2.86)$ & 0.51 \\
\hline - Basic & $13 / 724(1.8)$ & $0(0-0),[0-1,440]$ & $0.58(0.27-1.25)$ & 0.167 & $0.30(0.08-1.16)$ & 0.08 \\
\hline \multicolumn{7}{|l|}{ Environmental Factors } \\
\hline Elevation (in meters) & $n=6,134$ & 6,133 & & 0.02 & & 0.003 \\
\hline $1^{\text {st }}$ tertile $[-1 ; 15[$ & $63 / 2,094(3.0)$ & $0(0-0),[0-12,960]$ & Reference & & Reference & \\
\hline $2^{\text {nd }}$ tertile $[15 ; 30[$ & $37 / 2,300(1.6)$ & $0(0-0),[0-9,840]$ & $0.45(0.24-0.86)$ & 0.02 & $0.17(0.05-0.54)$ & 0.003 \\
\hline $3^{\text {rd }}$ tertile $[30 ; 61]$ & $99 / 1,740(5.7)$ & $0(0-0),[0-11,100]$ & $0.99(0.54-1.81)$ & 0.97 & $0.86(0.28-2.62)$ & 0.79 \\
\hline $\begin{array}{l}\text { Soil sand fraction at the } \\
\text { surface at } 0 \mathrm{~cm}(\%)\end{array}$ & $\mathrm{n}$ total $=6,134$ & 6,133 & & 0.01 & & 0.001 \\
\hline
\end{tabular}




\begin{tabular}{|c|c|c|c|c|c|c|}
\hline $1^{\text {st }}$ tertile $[35 ; 55[$ & $37 / 2,143(1.7)$ & $0(0-0),[0-1,176]$ & Reference & & Reference & \\
\hline $2^{\text {nd }}$ tertile $[55 ; 64[$ & $40 / 2,001(2.0)$ & $0(0-0),[0-3,624]$ & $1.14(0.61-2.12)$ & 0.67 & $1.50(0.49-4.61)$ & 0.48 \\
\hline $3^{\text {rd }}$ tertile $[64 ; 78]$ & $122 / 1,990(6.1)$ & $0(0-0),[0-12,960]$ & $2.45(1.29-4.66)$ & 0.006 & $8.60(2.53-29.19)$ & 0.001 \\
\hline $\begin{array}{l}\text { Soil acidity at everage depth } \\
(0-5-15 \mathrm{~cm})\end{array}$ & $\mathrm{n}$ total $=6,134$ & 6,133 & & 0.0351 & & 0.018 \\
\hline $1^{\text {st }}$ tertile $[4.8 ; 5.1[$ & $40 / 2,810(2.0)$ & $0(0-0),[0-11,100]$ & Reference & & Reference & \\
\hline $2^{\text {nd }}$ tertile $[5.1 ; 5.2[$ & $90 / 1,230(4.0)$ & $0(0-0),[0-9,840]$ & $1.93(1.15-3.24)$ & 0.01 & $3.47(1.32-9.16)$ & 0.012 \\
\hline $3^{\text {rd }}$ tertile $[5.2 ; 5.7]$ & 69/2,094 (3.7) & $0(0-0),[0-12,960]$ & $1.86(1.06-3.25)$ & 0.03 & $4.04(1.42-11.49)$ & 0.009 \\
\hline $\begin{array}{l}\text { MODIS daytime land surface } \\
\text { temperature mean for } 2018 \\
\text { ( }{ }^{\circ} \text { celsius) }\end{array}$ & $n=6,134$ & 6,133 & & 0.0082 & & 0.0002 \\
\hline $1^{\text {st }}$ tertile $[26.2 ; 29.6[$ & $71 / 2,097(3.4)$ & $0(0-0),[0-11,100]$ & Reference & & Reference & \\
\hline $2^{\text {nd }}$ tertile $[29.6 ; 31.9[$ & $109 / 2,407(4.5)$ & $0(0-0),[0-12,960]$ & $1.25(0.72-2.16)$ & 0.43 & $2.68(0.97-7.41)$ & 0.057 \\
\hline $3^{\text {rd }}$ tertile $[31.9 ; 32.8]$ & $19 / 1,630(1.2)$ & $0(0-0),[0-3,624]$ & $0.34(0.14-0.82)$ & 0.02 & $0.12(0.02-0.64)$ & 0.013 \\
\hline $\begin{array}{l}\text { MODIS Enhanced } \\
\text { Vegetation Index (EVI) mean } \\
\text { for } 2018\end{array}$ & $\mathrm{n}=6,134$ & 6,133 & & $<0.0001$ & & $<0.0001$ \\
\hline $1^{\text {st }}$ tertile $[0.04 ; 0.2[$ & $26 / 2,086(1.2)$ & $(0-0),[0-9,840]$ & Reference & & Reference & \\
\hline $2^{\text {nd }}$ tertile $[0.2 ; 0.3[$ & $35 / 2,061(1.7)$ & $(0-0),[0-3,624]$ & $1.42(0.74-2.72)$ & 0.29 & $2.23(0.70-7.08)$ & 0.174 \\
\hline $3^{\text {rd }}$ tertile $[0.3 ; 0.4]$ & $138 / 1,987$ (6.9) & $(0-0),[0-12,960]$ & $5.22(2.61-10.45)$ & $<0.001$ & $\begin{array}{l}42.41(11.88- \\
151.44)\end{array}$ & $<0.001$ \\
\hline $\begin{array}{l}\text { MODIS normalized } \\
\text { difference vegetation index } \\
\text { (NDVI) mean for } 2018\end{array}$ & $n=6,134$ & 6,133 & & $<0.0001$ & & $<0.0001$ \\
\hline $1^{\text {st }}$ tertile $[0.06 ; 0.3[$ & $27 / 2,063(1.3)$ & $(0-0),[0-9,840]$ & Reference & & Reference & \\
\hline $2^{\text {nd }}$ tertile $[0.3 ; 0.4[$ & $33 / 2,079(1.6)$ & $(0-0),[0-3,624]$ & $1.20(0.63-2.29)$ & 0.57 & $1.56(0.50-4.88)$ & 0.443 \\
\hline
\end{tabular}




\begin{tabular}{|c|c|c|c|c|c|c|}
\hline $3^{\text {rd }}$ tertile $[0.4 ; 0.6]$ & 139/1,992 (7.0) & $(0-0),[0-12,960]$ & $4.94(2.50-9.76)$ & $<0.001$ & $\begin{array}{l}36.18(10.25- \\
127.67)\end{array}$ & $<0.001$ \\
\hline Aridity index & $\mathrm{n}$ total $=6,134$ & 6,133 & & 0.28 & & 0.0977 \\
\hline $1^{\text {st }}$ tertile $[0.59 ; 0.61[$ & $81 / 2,083(3.9)$ & $(0-0),[0-9,840]$ & Reference & & Reference & \\
\hline $2^{\text {nd }}$ tertile $[0.61 ; 0.62[$ & $50 / 2,099(2.4)$ & $(0-0),[0-8,064]$ & $1.22(0.61-2.43)$ & 0.57 & $1.11(0.30-4.20)$ & 0.872 \\
\hline $3^{\text {rd }}$ tertile $[0.65 ; 0.65]$ & $68 / 1,952(3.5)$ & $(0-0),[0-12,960]$ & $1.84(0.84-4.00)$ & 0.12 & $3.64(0.89-14.83)$ & 0.071 \\
\hline
\end{tabular}

†Generalized estimating equations with exchangeable correlation structure and logit link applied

All data available displayed for "Infected with Hookworm/ total N (\%)"

Acronyms: School Aged Children (SAC), Pre School Aged Children (PSAC), confidence interval (CI), odds ratio (OR), Moderate Resolution Imaging

Spectroradiometer (MODIS) 

Table S4 : Intra-Class Correlation values

\begin{tabular}{|c|c|c|c|}
\hline Risk factor analysis & Model & Level of clustering & $\begin{array}{l}\text { Intra-Class } \\
\text { Correlation }(95 \% \mathrm{IC})^{*}\end{array}$ \\
\hline \multirow[t]{4}{*}{ Hookworm prevalence ${ }^{\star \star}$} & \multirow{2}{*}{$\begin{array}{l}\text { Model with age } \\
\text { and sex }\end{array}$} & Cluster level & $0.16(0.10-0.26)$ \\
\hline & & $\begin{array}{l}\text { Household within } \\
\text { Cluster level }\end{array}$ & $0.58(0.40-0.74)$ \\
\hline & \multirow{2}{*}{$\begin{array}{l}\text { Fully adjusted } \\
\text { model }\end{array}$} & Cluster level & $0.03(0.01-0.10)$ \\
\hline & & $\begin{array}{l}\text { Household within } \\
\text { Cluster level }\end{array}$ & $0.39(0.18-0.65)$ \\
\hline \multirow{4}{*}{$\begin{array}{l}\text { Ascaris lumbricoides } \\
\text { prevalence }{ }^{* *}\end{array}$} & \multirow{2}{*}{$\begin{array}{l}\text { Model with age } \\
\text { and sex }\end{array}$} & Cluster level & $0.54(0.34-0.73)$ \\
\hline & & $\begin{array}{l}\text { Household within } \\
\text { Cluster level }\end{array}$ & $0.60(0.38-0.78)$ \\
\hline & \multirow{2}{*}{$\begin{array}{l}\text { Fully adjusted } \\
\text { model }\end{array}$} & Cluster level & $0.42(0.23-0.64)$ \\
\hline & & $\begin{array}{l}\text { Household within } \\
\text { Cluster level }\end{array}$ & $0.51(0.26-0.76)$ \\
\hline
\end{tabular}

*The Intraclass correlation statistics reports two intraclass correlations for this three-level nested model. The first is the level-3 intraclass correlation at the cluster level, the correlation between Hookworm or Ascaris lumbricoides infection prevalence in the same cluster. The second is the level-2 intraclass correlation at the household-within-cluster level, the correlation between prevalence of infection with Ascaris lumbricoides in the same household and cluster.

** Generalized logistic mixed model with exchangeable correlation matrix 